\title{
A Thermally Coupled Reactive Distillation and Pervaporation Hybrid Process for n-Butyl Acetate Production with Enhanced Energy Efficiency
}

\author{
Gregorius Rionugroho Harvianto ${ }^{\mathrm{a}}$, Faizan Ahmad ${ }^{\mathrm{b}}$, Moonyong Lee ${ }^{\mathrm{a}}$, \\ aProcess Systems Design and Control Laboratory, School of Chemical Engineering, Yeungnam \\ University, Gyeongsan 712-749, Republic of Korea \\ ${ }^{\mathrm{b}}$ School of Science and Engineering, Teesside University, Middlesbrough, United Kingdom
}

Address: School of Chemical Engineering, Yeungnam University, Dae-dong 214-1, Gyeongsan 712-749, Republic of Korea

*Correspondence concerning this article should be addressed to:

Prof. Moonyong Lee

E-mail: mynlee@yu.ac.kr

Phone: +82538103241

Fax: +82538113262

\begin{abstract}
This paper presents a novel hybrid process combining thermally coupled reactive distillation with membrane-based pervaporation for enhanced production of n-butyl acetate. A conventional reactive distillation process was used as the base case and first optimized for the transesterification of methyl acetate with n-butanol to produce n-butyl acetate. It was observed that methyl acetate recovered in the recycle stream significantly affects the conversion in the reactive distillation column and overall energy efficiency of the whole process. The existing and proposed configurations were evaluated and optimized by simulation in Aspen Plus. The integration of
\end{abstract}


thermally coupled reactive distillation and pervaporation improved the energy efficiency of the reactive distillation process by preventing remixing effect in the reactive distillation column and eliminating the azeotropic nature of the methanol and methyl acetate in the recycle stream, respectively. Finally, integration of the thermally coupled reactive distillation with a commercial pervaporation membrane was explored to take synergistic advantage of the thermally coupled reactive distillation and pervaporation hybrid configuration. As a result, the proposed hybrid design showed remarkably improved energy efficiency and economics. The total reboiler duty and total annual cost reduced to 63 and $43 \%$, respectively, compared to those of the base case.

Keywords: n-butyl acetate production, reactive distillation, thermally coupled distillation, membrane hybrid distillation, process integration, process intensification 


\section{Introduction}

n-Butyl acetate is widely used in industry as a raw material for coatings and paints, a solvent for manufacturing lacquers, a synthetic fruit flavoring for food products, and as a reagent for pharmaceutical and cosmetic formulations (Liu et al., 2005). It could be prepared by the transesterification of n-butanol and methyl acetate, which is obtained as a byproduct from the polyvinyl alcohol (PVA) industry (Genduso et al., 2016). Until recently, methyl acetate had mainly been used for the production of acetic acid by reaction with water. However, as discussed in Lin et al. (2006), methyl acetate offers more economical benefits as a raw material for the production of n-butyl acetate by transesterification with n-butanol. The methanol obtained as the byproduct of this reaction may then be recycled back into a PVA production unit. Several studies have reported the kinetics and thermodynamics of this transesterification process using an Amberlyst15 catalyst (Bożek-Winkler and Gmehling, 2006; Jiménez et al., 2002; Steinigeweg and Gmehling, 2004).

The growing ecological concerns of society and the limitations of fossil fuel reserves pose many challenges for the energy-intensive chemical industry. Consequently, a general improvement in the energy efficiency of the n-butyl acetate industry is necessary to ensure its sustainability and allow it to overcome future challenges. Extensive research effort has been dedicated to retrofitting the n-butyl acetate production process and improving its energy efficiency. For example, Jiménez and Costa-López (2002) proposed a scheme in which methyl acetate is converted into n-butyl acetate by a system comprising reactive and extractive distillation units. The complexity of this process is due to the occurrence of two azeotropes, one between methanol and methyl acetate (at $66.7 \mathrm{~mol} \%$ methyl acetate) and one between n-butyl acetate and butanol (at $78.01 \mathrm{~mol} \%$ butanol). 
This reactive-extractive distillation technique needs an additional component (xylene) as an extraction agent.

Reactive distillation (RD), which combines the reaction and separation processes into a single unit, offers a significant reduction in both energy and equipment costs and is gaining popularity, largely because of its promise for reversible reactive systems in which a chemical equilibrium limits conversion (Jiménez and Costa-López, 2002). A single reactive distillation column can replace conventional multi-unit processes that require five times more energy and capital investment (Taylor and Krishna, 2000). In addition, the thermally coupled distillation (TCD) technique has proven to be an attractive method for reducing both the energy and capital costs of distillation processes. TCD sequences are obtained through the implementation of interconnecting streams (one in the liquid phase and the other in the vapor phase) between two columns. Each interconnection replaces one condenser or one reboiler from one of the columns, providing potential capital and energy cost savings (Long and Lee, 2014; Van Duc Long and Lee, 2013).

Luyben et al. (2004) has proposed a reactive distillation process for the enhanced production of nbutyl acetate with a simpler process structure consisting of only three distillation columns that showed significant improvement in the energy efficiency. Wang et al. (2008) combined the reactive distillation and thermally coupled distillation techniques and developed thermally coupled reactive distillation (TCRD) as an attractive strategy to reduce the energy requirement of the distillation columns in n-butyl acetate production. However, all of these configurations have similar drawbacks in that methyl acetate and methanol are recycled back to the main reactive distillation column as azeotropes, which limits the reaction and energy efficiency of the reactive distillation column. 
Pervaporation (PV), or vapor permeation, of organic mixtures has been widely used in industry to overcome difficulties with mixtures such as azeotropes or close-boiling mixtures (Kujawski, 2000; Naidu and Malik, 2011), and it is considered to be a good technique for separating methanol from methyl acetate (Sain et al., 1998). Steinigeweg and Gmehling (2004) and Švandová and Markoš (2011) have reported experimental and simulation studies on the integration of reactive distillation and pervaporation separation for n-butyl acetate production. They proved that in order to increase the conversion of methyl acetate to n-butyl acetate, the recycle stream to the reactive distillation column should be concentrated into pure methyl acetate. However, their work assumed an ideal pervaporation process. An ideal separation process, which relies on the selectivity of the membrane used in the experiment, was not possible with their specific membrane area to fulfill the high purities required for methyl acetate in the retentate and methanol in the permeate.

This work implements a novel hybrid system combining advanced distillation (such as TCD and reactive distillation) with pervaporation as a technology for the enhanced production of n-butyl acetate. This hybrid process aims to exploit the benefit of each process synergistically into a single comprehensive system. Fig. 1 provides an outline of the design approach used in this study to achieve this objective. A TCRD process for the production of n-butyl acetate is first designed using a new design procedure, with the purpose of optimizing the design from an energy efficiency viewpoint. The innovation of this method is that it involves the hybrid of TCRD with pervaporation membrane. The integrated process here is called TCRD+PV hybrid system. To the authors' knowledge, there is no literature that investigates the combination of this technique in one integrated process. For this purpose, a commercial pervaporation membrane was used owing to its market availability. The proposed configuration of the TCRD+PV hybrid system was then compared with all previous techniques to demonstrate its performance. Therefore, the energy 
efficiency and economics of butyl acetate production process could be improved by applying the proposed hybrid design to separate the components of the azeotrope in order to increase the conversion as well as reduce the energy demand of the process. The combination of these advanced separation processes can be extended to numerous chemical industrial plants as an attractive and interesting concept.

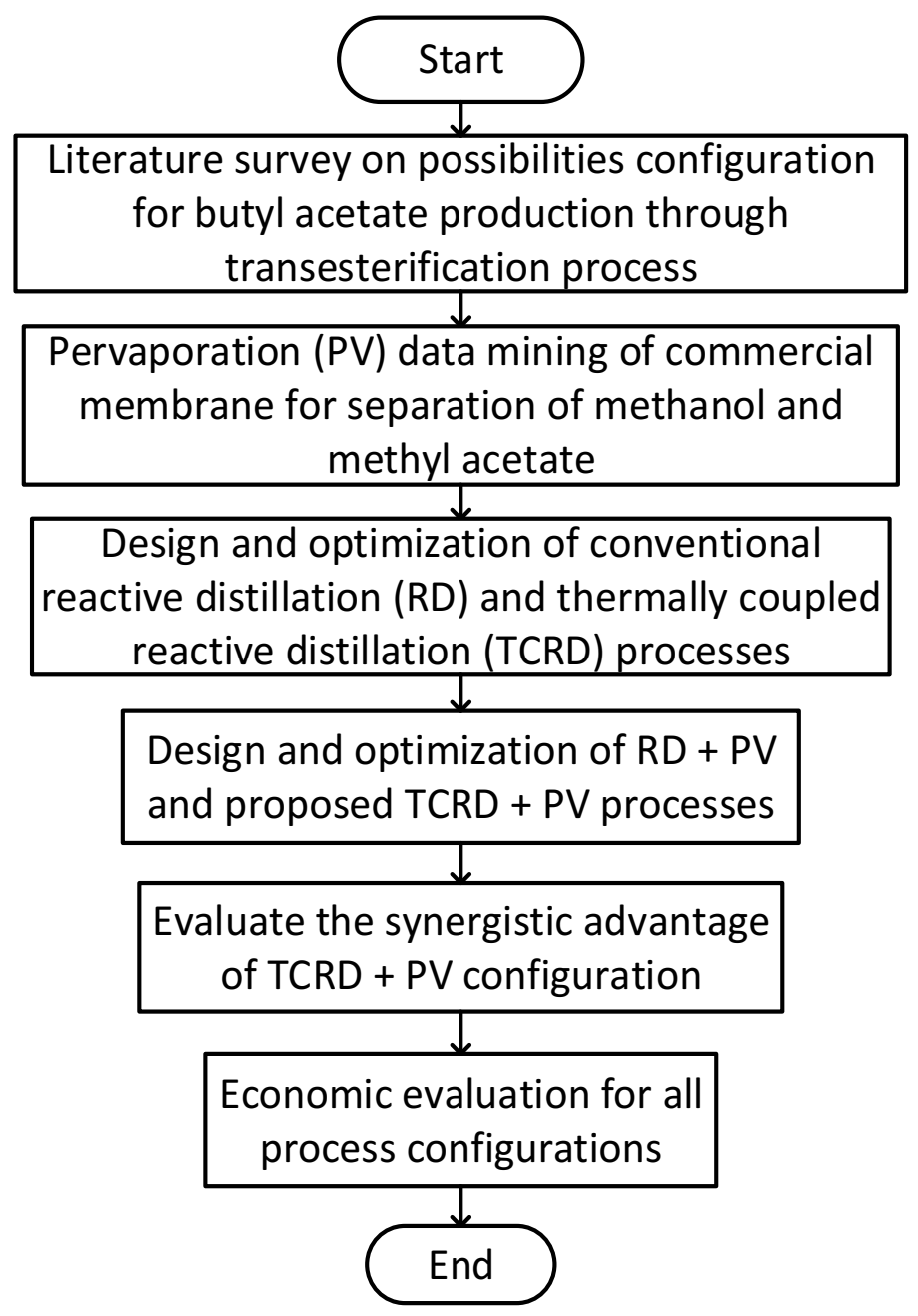

Fig. 1. Flowchart of design approach used in this study 


\section{Comparison of conventional and proposed hybrid designs}

As mentioned earlier, reactive distillation has been proven to enhance the production of n-butyl acetate. From the previous work (Wang et al., 2008), the reboiler duty could be significantly reduced by replacing the conventional multi-unit process (Jiménez and Costa-López, 2002) with the conventional reactive distillation. Fig. 2 shows a conventional reactive distillation process consisting of a reactive distillation column and a methanol column (RD+MC) where N-butyl acetate is withdrawn as product from the bottom stream of reactive distillation column. Methyl acetate and methanol are taken from the top stream of the methanol column at the azeotrope composition and recycled to the reactive distillation column. This conventional reactive distillation process provides an attractive alternative to the conventional process (Luyben et al., 2004) and the reactive-extractive distillation process (Jiménez and Costa-López, 2002) that requires more than four columns to fulfill product specifications.

Owing to the high energy required for the conventional reactive distillation process, several researchers have proposed retrofit designs to reduce operating costs. These retrofit designs can be divided into two categories: The first obtains pure methyl acetate as the recycle stream by adding a pervaporation membrane between the reactive distillation and methanol columns ( $\mathrm{RD}+\mathrm{PV}+\mathrm{MC})$. This design offers higher performance in terms of n-butyl acetate conversion in the reactive section, which reduces the reboiler duty in the reactive distillation column (Steinigeweg and Gmehling, 2004; Švandová and Markoš, 2011). The second design involves thermally coupling the reactive distillation column and the side-stripper (SS) column, i.e., a TCRD configuration (Wang et al., 2011; Wang et al., 2008). N-butyl acetate is also taken from the bottom stream of the reactive distillation column and the methanol is withdrawn from the SS column. In this design, methyl acetate and methanol are recycled at its azeotrope composition, similarly to the 
conventional reactive distillation process. The advantage of TCRD is the elimination of the condenser in the methanol column and the high energy saving for the whole process.

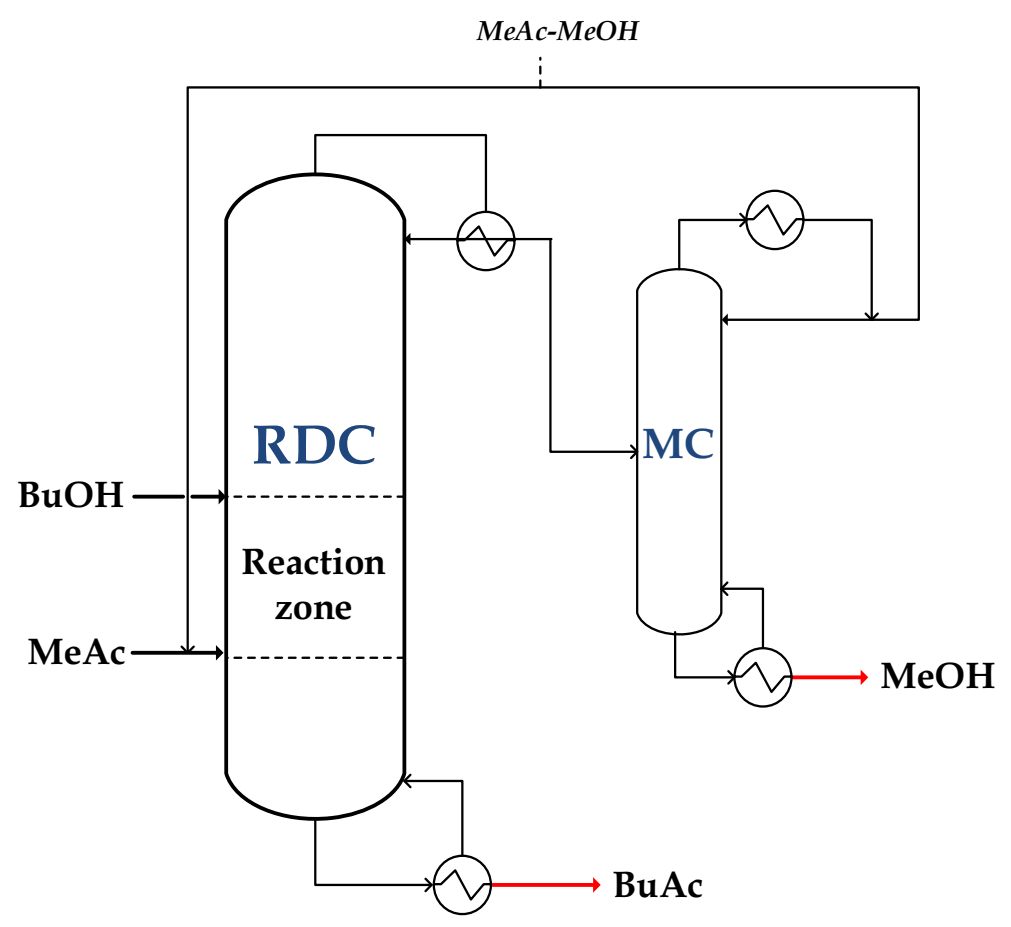

Fig. 2. Conventional reactive distillation process $(\mathrm{RD}+\mathrm{MC})$ for n-butyl acetate production

In order to exploit all the benefits of the designs, this work proposes a combination of both, i.e., thermally coupled reactive distillation with pervaporation (TCRD+PV). Fig. 3 shows the proposed TCRD+PV configuration compared with the existing RD+PV and TCRD configurations. In the proposed TCRD+PV configuration, the reactive distillation column is thermal coupled to the SS column, and nearly pure methyl acetate is fully recovered as the retentate from pervaporation and fed back to the reactive distillation column. To solve the methanol-methyl acetate azeotrope problem in the distillate stream of the reactive distillation column, this work uses a commercial pervaporation membrane owing to its market availability. This intensified design is expected to 
reduce both operating and capital costs. A detailed design of the proposed configuration is given in section 5 .

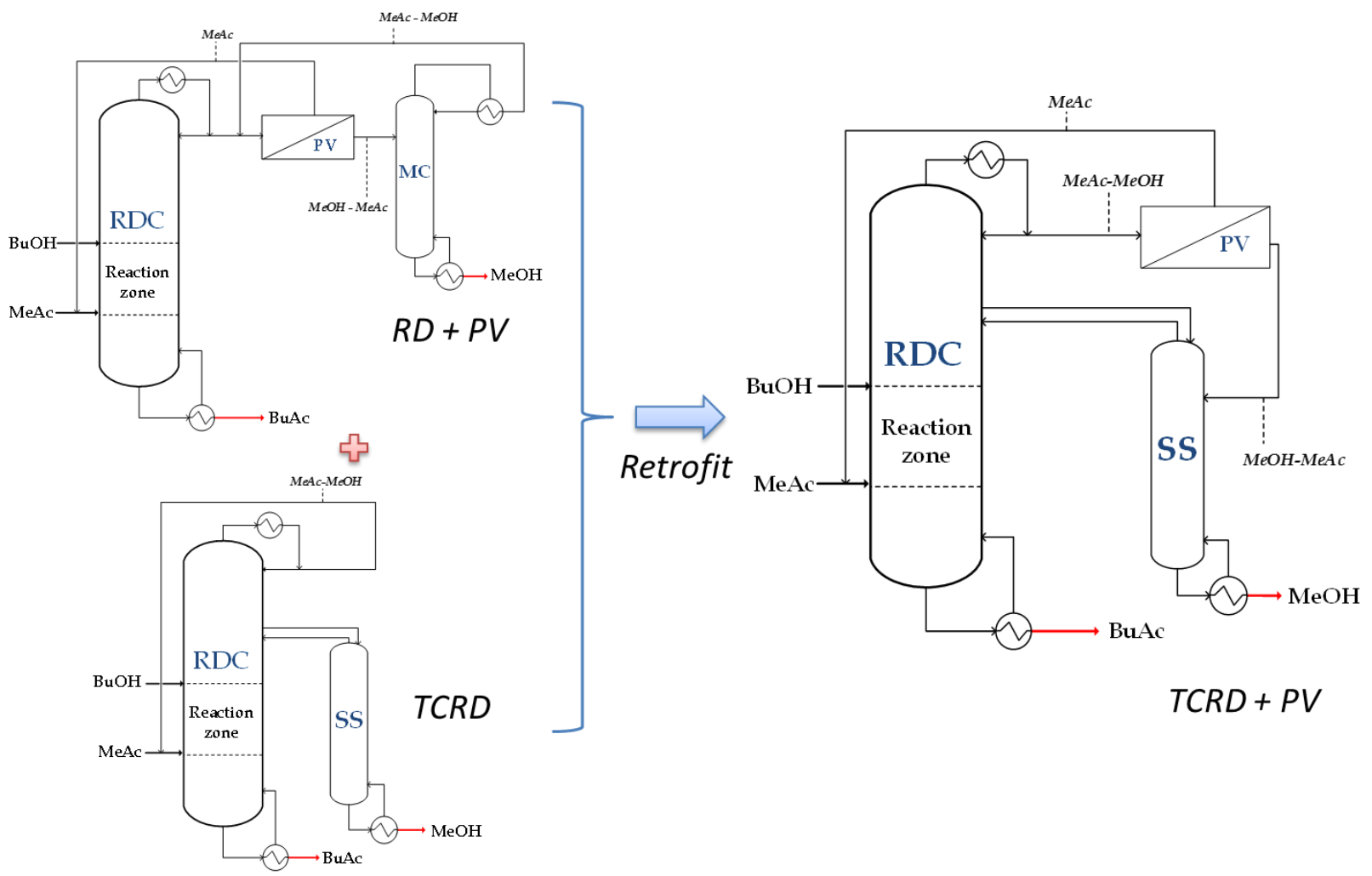

Fig. 3. Proposed system for thermally coupled reactive distillation with pervaporation (TCRD+PV)

\section{Pervaporation membrane for methanol-methyl acetate separation}

The separation performances of numerous different commercial membranes have been evaluated for this system in several research works dealing with pervaporation of methanol-methyl acetate mixtures (Gorri et al., 2006; Sain et al., 1998; Steinigeweg and Gmehling, 2004). Table 1 summarizes the currently available commercial pervaporation membranes that can be used for this system. A high concentration of methanol can be obtained in the permeate stream using these methanol-selective membranes. Table 1 also compares the performance of each membrane for the 
same feed specification. The feed used for comparison is an azeotropic methanol-methyl acetate mixture (20 wt $\%$ or $36 \mathrm{~mol} \%$ of methanol).

Table 1. Summary of available pervaporation membranes for methanol-methyl acetate separation at the same feed composition ( $20 \mathrm{wt} \%$ of methanol)

\begin{tabular}{|c|c|c|c|c|c|}
\hline Membrane & $\begin{array}{l}\text { Temp. } \\
\left({ }^{\circ} \mathrm{C}\right)\end{array}$ & $\begin{array}{l}\text { Total flux } \\
\left(\mathrm{kg} / \mathrm{m}^{2} \mathrm{~h}\right)\end{array}$ & $\begin{array}{c}\text { Permeate } \\
\text { (wt\% methanol) }\end{array}$ & $\begin{array}{l}\text { Separation } \\
\text { factor }\end{array}$ & References \\
\hline Cuprophane & 45 & 0.453 & 66.5 & 7.9 & (Sain et al., 1998) \\
\hline Pervap 2255-40 & 45 & 4.125 & 42.0 & 2.9 & $\begin{array}{l}\text { (Steinigeweg and } \\
\text { Gmehling, 2004) }\end{array}$ \\
\hline Pervap 2255-50 & 45 & 1.375 & 56.4 & 5.2 & $\begin{array}{l}\text { (Steinigeweg and } \\
\text { Gmehling, 2004) }\end{array}$ \\
\hline Pervap 2255-60 & 45 & 0.65 & 58.7 & 5.7 & $\begin{array}{l}\text { (Steinigeweg and } \\
\text { Gmehling, 2004) }\end{array}$ \\
\hline Pervap 2255-30 & 40 & 2.44 & 54.4 & 4.8 & (Gorri et al., 2006) \\
\hline PolyAl TypM1 & 44 & 8.1 & 34.5 & 2.6 & (Genduso et al., 2016) \\
\hline
\end{tabular}

This work aims to evaluate the performance of commercial pervaporation membranes once coupled with an advanced distillation technique. As can be seen from the Table 1, the commercial membranes that have been evaluated for this system are Cuprophane (Sain et al., 1998) and Pervap 2255 (Gorri et al., 2006; Steinigeweg and Gmehling, 2004). However, all of these commercial membranes have low selectivity to obtain two different products in two output streams. Thus, the purpose of these pervaporation membranes is only to obtain high-purity methyl acetate in the retentate stream by employing a high membrane area. Then, the permeate stream must be sent to a distillation column to separate the methanol and methyl acetate further. Flux value is an essential 
parameter in membrane design to determine the required membrane area. A low flux value can cause a higher membrane area, leading to higher capital cost of the membrane. Sulzer Chemtech is one of market leaders that produces PERVAP ${ }^{\circledR}$ plate-frame pervaporation and vapor permeation units and installed them in 110 plants in the year 2000 (Kujawski, 2000). Therefore, in this work, Pervap 2255-40 membrane produced by Sulzer Chemtech was chosen as the best representative commercial pervaporation membrane owing to its high flux. For cost evaluation of the hybrid process configurations, a plate and frame module was used as the membrane module. From the literature, the plate and frame module is a standard design for pervaporation on an industrial scale. In this kind of module, the membranes are supported by stainless steel perforated plates and spacers, which form the permeate channels, allowing for fast and easy removal of permeate. This module is specially designed for the high-temperature processing of volatile organics such as alcohols and other solvents (Sulzer Chemtech, 2004).

\section{Simulation and optimization methods}

\subsection{Process simulation}

The feasibility of process candidates for n-butyl acetate production was examined by rigorous simulation and optimization in Aspen Plus. However, since no model for a membrane separation system is available in commercial process simulators such as Aspen Plus and Aspen Hysys, a rigorous mathematical model for the pervaporation process was developed based on a solutiondiffusion model similar to that used in previous hybrid distillation membrane work (Harvianto et al., 2016) and validated to model the pervaporation under different feed conditions. The pervaporation model was implemented using the Excel-VBA interface and integrated with Aspen 
Plus, which was used to calculate the mass and energy balances and combine the process flowsheet. The pervaporation model developed can assess the permeate and retentate of the system with any number of permeability and membrane areas to allow complex process simulations. The input variables of the model include the permeability data of methyl acetate and methanol as a function of their concentration in the feed stream, feed temperature, membrane thickness, and permeate pressure. The values of the input variables were obtained from published literature (Steinigeweg and Gmehling, 2004).

The universal quasichemical (UNIQUAC) model (Abrams and Prausnitz, 1975) was chosen for calculating the activity coefficient for the liquid phase non-idealities. Due to the relatively low pressure $(1 \mathrm{~atm})$ in the following design, vapor phase non-idealities were neglected during the vapor-liquid equilibrium (VLE) calculation (Steinigeweg and Gmehling, 2004). All components and their VLE binary interaction parameters erre available in Aspen Plus data bank. There are four components (methyl acetate, butanol, n-butyl acetate, and methanol) in the system, among which there are two pairs of azeotrope at $1 \mathrm{~atm}$. The boiling point of pure components and the azeotropic data predicted from UNIQUAC at $1 \mathrm{~atm}$ are shown in Table 2.

Table 2. Boiling points of pure components and azeotropes at $1 \mathrm{~atm}$.

\begin{tabular}{lll}
\hline Name & Boiling point $\left({ }^{\circ} \mathbf{C}\right)$ & Azeotropic composition (mole basis) \\
\hline Methyl acetate & 56.94 & \\
Butanol & 118.75 & \\
n-Butyl acetate & 126.11 & \\
Methanol & 64.7 & $0.6659 / 0.3341$ \\
Methyl acetate/methanol & 53.64 & $0.2198 / 0.7802$ \\
Butyl acetate/butanol & 116.98 & \\
\hline
\end{tabular}


The feed composition, temperature, pressure, flow rate, column pressure, and product requirement were considered the same as in previous studies (Wang et al., 2011) for comparison. Table 3 lists the operating conditions and product requirements, which were commonly applied to all designs compared in this study. The design specification function in Aspen Plus was used to achieve the qualities of product streams in the distillation column and minimize the reflux ratio. The pervaporation membrane area was calculated with the requirement of 99.9 mol\% methyl acetate in the retentate. This calculation can be performed using the flowsheet design specification function in Aspen Plus.

Table 3. Feed mixture conditions and product requirements.

\begin{tabular}{ll}
\hline Variable & Value \\
\hline Feed flow rate & $100 \mathrm{kmol} / \mathrm{h}$ of methyl acetate \\
& $100 \mathrm{kmol} / \mathrm{h}$ of $\mathrm{n}$-butanol \\
Feed and column pressure & $1 \mathrm{~atm}$ \\
Feed temperature & methyl acetate: $25^{\circ} \mathrm{C}$ \\
& n-butanol: $118^{\circ} \mathrm{C}$ (saturated vapor) \\
Product requirement & $100 \mathrm{kmol} / \mathrm{h}$ of n-butyl acetate $\geq 99.5 \mathrm{~mol} \%$ \\
& $100 \mathrm{kmol} / \mathrm{h}$ of methanol $\geq 99.5 \mathrm{~mol} \%$ \\
Catalyst & $500 \mathrm{~g} / \mathrm{stage}$ in reactive zone \\
\hline
\end{tabular}

The transesterification reaction of methyl acetate and n-butanol proceeds as follows:

$$
n-\text { butanol }+ \text { methyl acetate } \leftrightarrow n-\text { butyl acetate }+ \text { methanol }
$$

The reaction takes place in the liquid phase. n-Butyl acetate and methanol are the high and low boiling point products, respectively. The conversion of n-butanol to n-butyl acetate is strongly limited by the equilibrium reaction. This reversible reaction needs to be catalyzed by strong acids. The kinetic data for the process in the presence of an Amberlyst-15 catalyst were reported by 
Jiménez et al. (2002), and a pseudo-homogeneous model was also given:

$$
\begin{gathered}
r=k \exp \left(\frac{E a}{R T}\right) C_{n-\text { вион }} C_{\text {MeAc }} \\
r_{1}=2.018 \times 10^{8} \exp \left(\frac{71960}{R T}\right) C_{n-B u O H} C_{M e A c} \\
r_{2}=2.839 \times 10^{8} \exp \left(\frac{72670}{R T}\right) C_{B u A C} C_{M e O H}
\end{gathered}
$$

where $r_{1}$ and $r_{2}$ are the reaction rates for the forward and backward reactions, respectively, $k$ is the reaction constant $\left(\mathrm{L} / \mathrm{mol} \cdot \mathrm{min} \cdot \mathrm{g}_{\mathrm{cat}}\right), E a$ is the activation energy $(\mathrm{J} / \mathrm{mol}), R$ is the gas constant $(\mathrm{J} / \mathrm{mol} \cdot \mathrm{K}), T$ is the temperature $(\mathrm{K})$ and $C_{i}$ is the concentration of component $i(\mathrm{~mol})$.

Note that the pressures for all unit operations were set to 1 atm considering the temperature limitation of Amberlyst-15. To maintain the stability of the catalyst, the reaction zone temperature must be below $120^{\circ} \mathrm{C}$ ( $\mathrm{Lu}$ et al., 2006). This temperature can be maintained by adjusting the pressure in the range $1-1.5 \mathrm{~atm}$ in the reactive distillation column.

The simulation of transesterification distillation was carried out using the distillation model "RadFrac" provided by Aspen Plus v.9 software. This model is based on a rigorous equilibrium stage model for solving the MESH equations (Schefflan, 2011). In the "RadFrac, instead of conventional distillation input parameters, the reaction input parameters and the reactive stages must be given. The reaction is incorporated with the "RadFrac" model in which Aspen calculates the equilibrium constant by minimizing the Gibbs free energy. The stages are numbered from top to bottom with the condenser being the first stage and the reboiler being stage N. Since the work by Wang et al. (2011) is the most recent to propose a TCRD configuration and reports the highest energy efficiency for this transesterification process, the structures (total number of stages and feed location) for the conventional reactive distillation and TCRD configurations used in this study were chosen to be the same as in their work. 


\subsection{Sensitivity analysis and process optimization}

Sensitivity analysis was conducted for conventional reactive distillation (i.e., RD+MC) and TCRD sequences to identify the decision variables that could be optimized to improve the process. For conventional reactive distillation and $\mathrm{RD}+\mathrm{PV}+\mathrm{MC}$, both reactive distillation and methanol columns have two degrees of freedom that can be used as design specifications: the bottom flow rate of the distillation column, and the reflux ratio. The bottom flow rates for both the reactive distillation and methanol columns were defined as the required output flow rate $(100 \mathrm{kmol} / \mathrm{h})$ of n-butyl acetate and methanol, respectively, and the reflux ratio was chosen to meet the purity specification required. Therefore, all configurations have recycled flow rates (i.e., the distillate stream from the methanol column and/or the retentate stream from the membrane) that have been used as the remaining degree of freedom to minimize the total reboiler duty of the process.

Furthermore, in the TCRD and TCRD+PV configurations, both the reactive distillation and sidestripper columns have degrees of freedom: the two bottom flow rates (chosen to be the same flow rate as those in the conventional configuration), reflux ratio of the reactive distillation column, split ratio, and recycle flow rate. The split ratio is the ratio of the liquid flow directed to the sidestripper column and that to the reactive distillation column. In this work, the two bottom flow rates were defined as the product output flow rate required $(100 \mathrm{kmol} / \mathrm{h})$, and the reflux ratio was used to satisfy the purity specification. As the remaining degrees of freedom, the recycle flow rate and split ratio were used as optimization variables to minimize the total reboiler duty of the process.

The sensitivity analysis results, which will be discussed in section 5 , show that the total reboiler duty of both the reactive distillation and methanol columns (or side-stripper column) mainly depend on the flow rate and the composition of the recycle stream and/or the liquid split ratio (only 
for TCRD sequences). The main focus, therefore, was on evaluating the impact of the recycle stream and split ratio on the energy consumption. For all configurations studied in this work, the decision variables were optimized using the process optimization tool based on a sequential quadratic programming (SQP) algorithm (Al-Malah, 2016; Schefflan, 2011) in Aspen Plus coupled with the sensitivity analysis tool. It was shown that the SQP algorithm is globally and locally super-linearly convergent (Biegler and Cuthrell, 1985; Boggs and Tolle, 1995). The SQP method has been accepted as a successful method for solving nonlinearly constrained optimization problems, and it has been successfully employed in several previous studies (Ignat and Kiss, 2013; Kiss and Ignat, 2012; Kiss and Suszwalak, 2012; More et al., 2010). The optimal design for each configuration in this work was obtained by the minimization of total reboiler duty with the optimizing variables that mentioned earlier.

\section{Results and discussion}

\subsection{Design and optimization of the conventional RD+MC process}

Wang et al. (2011) proposed a conventional reactive distillation process for the production of $\mathrm{n}$ butyl acetate consisting of two columns: a reactive distillation and a methanol column. In their conventional reactive distillation configuration, the reactive distillation column is fed with fresh butanol, fresh methyl acetate, and a recycle stream delivering an azeotropic mixture of methyl acetate and methanol. The reactive distillation column produces the butyl acetate product from the bottom of the column. The distillate containing mostly methanol with methyl acetate goes to the methanol column where the methanol is removed as the bottom product and the distillate is 
recycled to the reactive distillation column. The distillate from the methanol column has an approximately homogeneous azeotropic composition of methanol and methyl acetate mixtures.

The overall reaction conversion and energy efficiency can be significantly improved through proper optimization for a given process structure. In this study, the conventional reactive distillation process was further optimized to obtain the minimum energy requirement. The detailed structure (the number of trays and feed locations) of each column, as well as the recovery and purity of the final products, are same as those employed by Wang et al. (2011). In particular, a sensitivity analysis was performed on the recycle stream (i.e., the distillate from the methanol column), which can significantly change the characteristics of the process. Figs. 4 and 5 show the effect of recycle flow rate on the reboiler duty, product concentration, and unreacted methyl acetate flow rate in the conventional reactive distillation configuration.

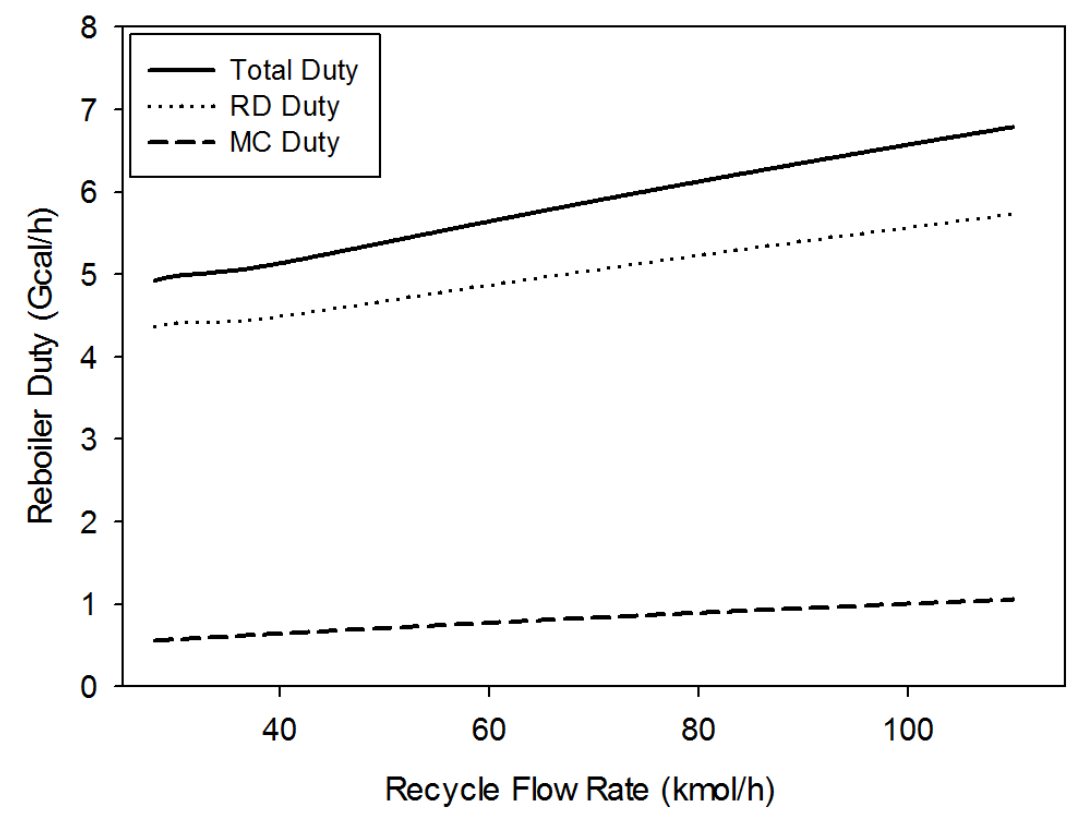

Fig. 4. Effect of recycle flow rate on reboiler duty in the conventional reactive distillation configuration 
As can be seen in Fig. 4, the recycle flow rate significantly affects the reboiler duty of both the reactive distillation and methanol columns, and a low reboiler duty was attained with a low recycle flow rate. In the butyl acetate production process, the reactive distillation unit is implemented to perform the transesterification reaction by focusing on the forward reaction to produce butyl acetate. With a high recycle flow rate, high methanol concentration in the reactive distillation column enhances the backward reaction back to produce methyl acetate. As shown in Fig. 5, the amount of unreacted methyl acetate in the distillate stream is decreased with a lower recycle flowrate, which leads to a lower reboiler duty. Moreover, the low recycle flow rate enhances the methanol concentration in the distillate stream of the reactive distillation column. Since the distillate of reactive distillation column was fed to the methanol column to obtain the methanol as the bottom product, the requirement of reboiler duty in the methanol column also reduced.

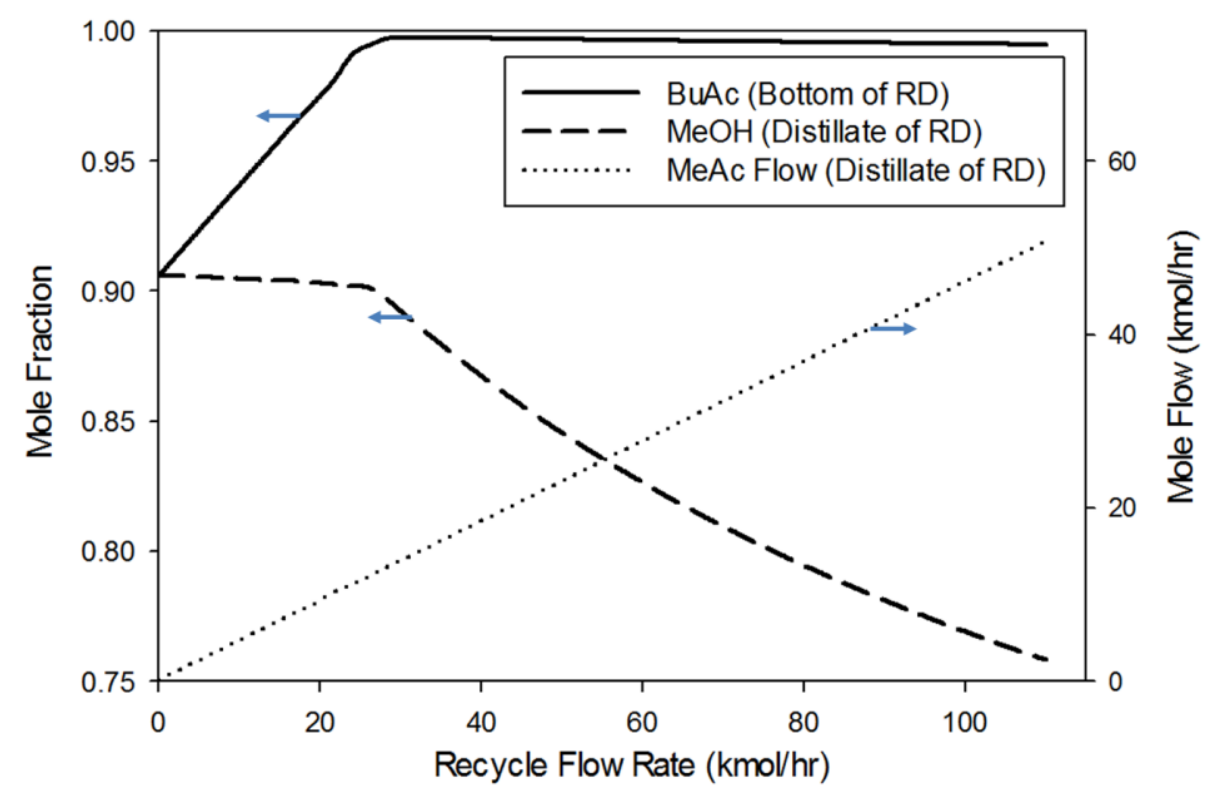

Fig. 5. Effect of recycle flow rate on the product concentration and unreacted methyl acetate flow rate of the reactive distillation column in the conventional reactive distillation configuration 
All reports in the process design literature for this kind of transesterification system (Jiménez and Costa-López, 2002; Luyben et al., 2004; Wang et al., 2011; Wang et al., 2008) assert that the recycle stream is important to provide excess methyl acetate to the transesterification reaction. The sensitivity analysis results in Fig. 5 also show that the recycle flow rate needs to be higher than $\sim 28 \mathrm{kmol} / \mathrm{h}$ to accomplish the required product specifications. Note that the sensitivity analysis was performed using the recycle stream flow rate and concentration obtained earlier (Wang et al., 2011). The purity of the butyl acetate in the bottom product becomes less than $99.5 \mathrm{~mol} \%$ when the recycle flow rate is less than $\sim 28 \mathrm{kmol} / \mathrm{h}$. This indicates that some excess methyl acetate has to be provided from the recycle stream to allow high reaction conversion and fulfill product purity in the outlet stream. In this study, the recycle stream flow rate of the methanol-methyl acetate mixture was optimized to obtain the lowest total reboiler duty by using the Aspen Plus built-in optimization function. Fig. 6 shows the resulting mass and energy balance after optimization. The total reboiler duty is drastically reduced from 6.7 to $3.47 \mathrm{Gcal} / \mathrm{h}$ once the recycle stream is optimized (from 104.7 to $22.6 \mathrm{kmol} / \mathrm{h}$ ). This significant reduction of energy consumption is not only due to the reduced recycle flow rate but also because of the increased concentration of methyl acetate (from 61.7 to $64.4 \mathrm{~mol} \%$ ) recycled to the reactive distillation column. This enhances the reaction conversion in the reactive distillation column, which leads to low reboiler duty for the reactive distillation column. In addition, the distillate of the reactive distillation column has a higher methanol concentration ( $87.7 \mathrm{~mol} \%)$ than that in the previous work (68.2 mol\%) (Wang et al., 2011), which results in a low reboiler duty in the methanol column. 


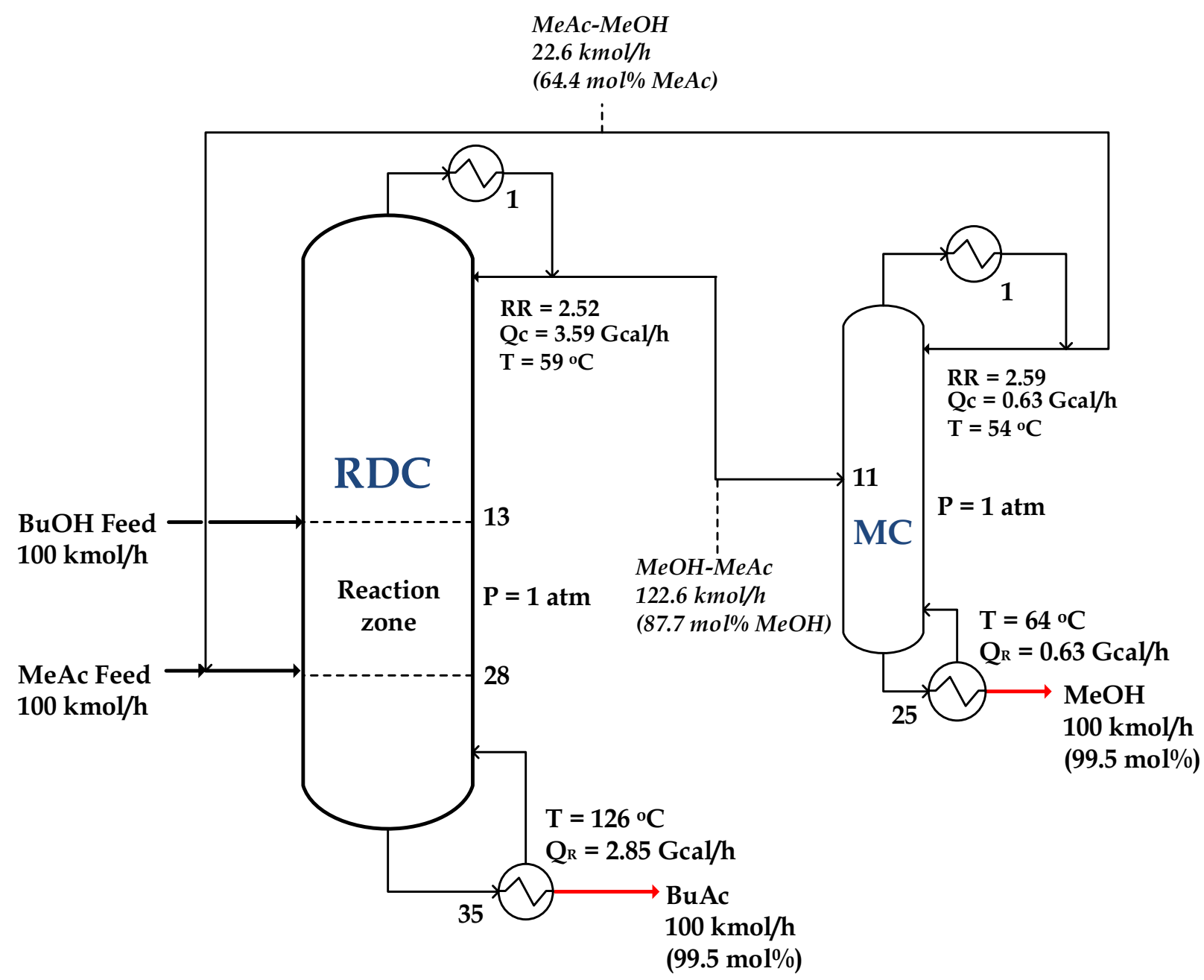

Fig. 6. Optimized conventional reactive distillation process

\subsection{Design and optimization of TCRD configuration (RD+SS)}

Wang et al. (2008) proposed a TCRD configuration (RD+SS) involving thermal coupling of the reactive distillation and methanol columns to improve the energy efficiency of the conventional reactive distillation process. In the TCRD configuration, butyl acetate is also withdrawn from the bottom of the reactive distillation column, as with the conventional reactive distillation configuration, but a side-draw stream is withdrawn from the reactive distillation column to supply 
the liquid stream to the SS column. Since the function of this side-draw stream is to purge the highpurity methanol product $(99.5 \mathrm{~mol} \%)$ from the bottom stream of the side-stripper column, the location of the side-draw stream was decided by selecting the stage with the maximum methanol composition with reference to the composition profile of the reactive distillation column during a simulation. The structure (the number of stages, the feed, and the side draw stage location) of each column was optimized in the TCRD configuration. In their study, the TCRD configuration reduced the total reboiler duty by $14 \%$ compared with that in their conventional reactive distillation configuration (from 6.7 to $5.76 \mathrm{Gcal} / \mathrm{h}$ ).

In the TCRD sequence, in addition to the flow rate of the recycle stream, the split ratio of the liquid flow withdrawn from the reactive distillation to the side-stripper column is also an important variable to be optimized. Sensitivity analysis was performed to examine the effect of the split ratio on the reboiler duty in the TCRD configuration. As seen in Fig. 7, the split ratio have significant influences on the total reboiler duty of the TCRD process. At the recycle flow rate of $98.3 \mathrm{kmol} / \mathrm{h}$ obtained from the previous work (Wang et al., 2011), the liquid split ratio affects the reboiler duty of each column in opposite directions. Although the reboiler duty of the side-stripper column increases slightly with a lower split ratio, the reduction in the duty of the reactive distillation column is dominant and thus the total reboiler duty decreases. However, the operation becomes infeasible when the split ratio becomes too low. Fig. 7 shows the range of the split ratio that provides sufficient product purities and flow rates of butyl acetate and methanol. The reboiler duty of the side-stripper column in the TCRD is a weak function of the split ratio because the components in the system have very similar molar latent heat of vaporization values, as observed earlier for the conventional thermally coupled distillation structure (Beneke and Linninger, 2011). 
In this work, the TCRD configuration was optimized to fully utilize the potential of the TCRD configuration while the structures of each column in the TCRD remained same as those in the previous work by Wang et al. (2008). Fig. 8 shows the mass and energy balance of the optimized TCRD process $(\mathrm{RD}+\mathrm{SS})$. The energy efficiency of the TCRD configuration is greatly improved by optimizing both the recycle stream flow rate and the liquid split ratio. The total reboiler duty is dramatically reduced (from 5.76 to $3.16 \mathrm{Gcal} / \mathrm{h}$ ) when the recycle stream (distillate from the reactive distillation column) is optimized to $29.4 \mathrm{kmol} / \mathrm{h}$, which is much lower than that in the previous work, i.e., $98.3 \mathrm{kmol} / \mathrm{h}$ (Wang et al., 2011), but it still provides sufficient methyl acetate as the reactant. In addition, the increased methanol concentration $(94.2 \mathrm{~mol} \%)$ in the split stream to the side-stripper column contributes to a reduction in the reboiler duty for the side-stripper column (from 1.49 to $0.44 \mathrm{Gcal} / \mathrm{h}$ ).

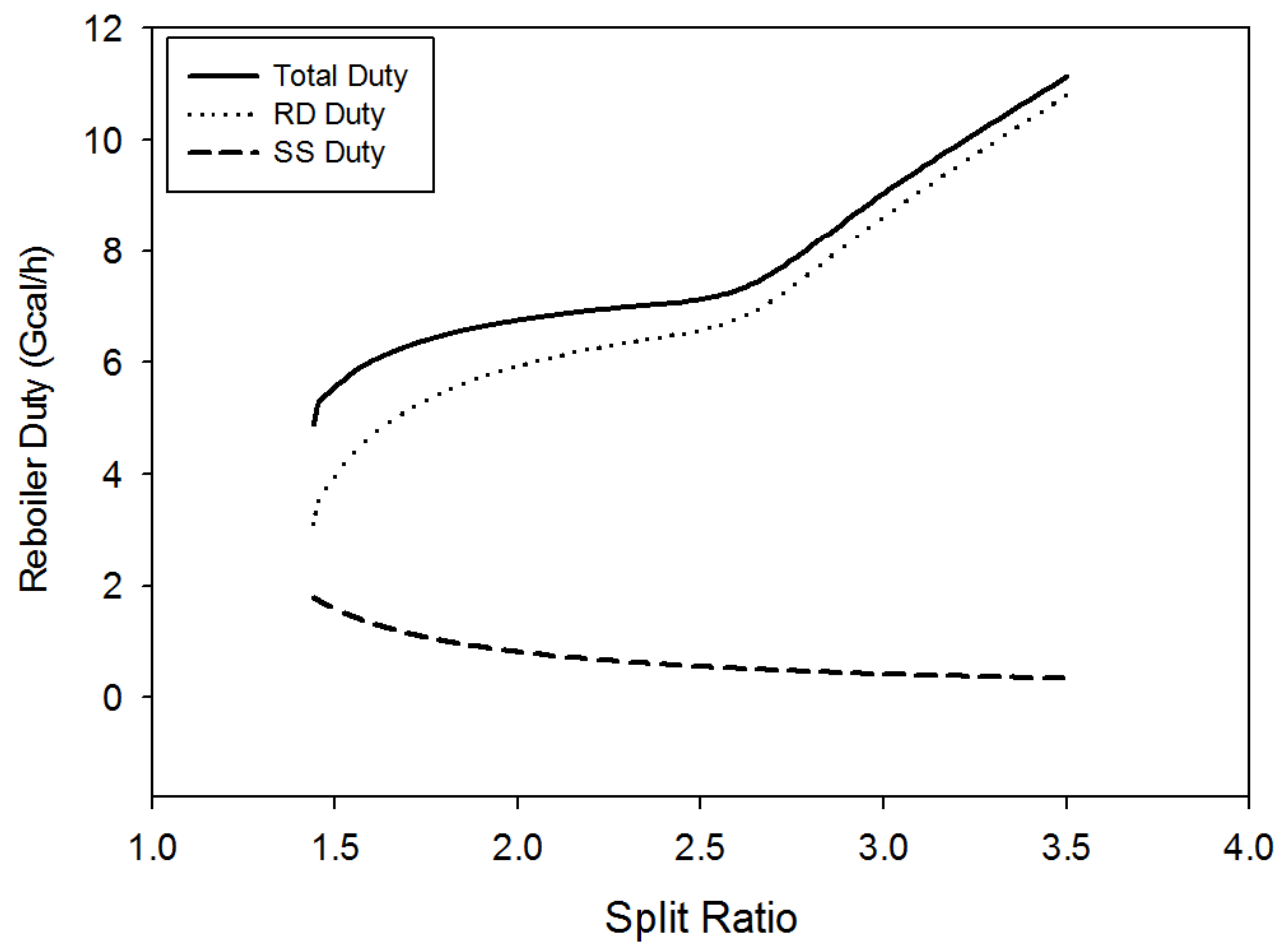

Fig. 7. Effect of liquid split ratio on the reboiler duty in the TCRD configuration 


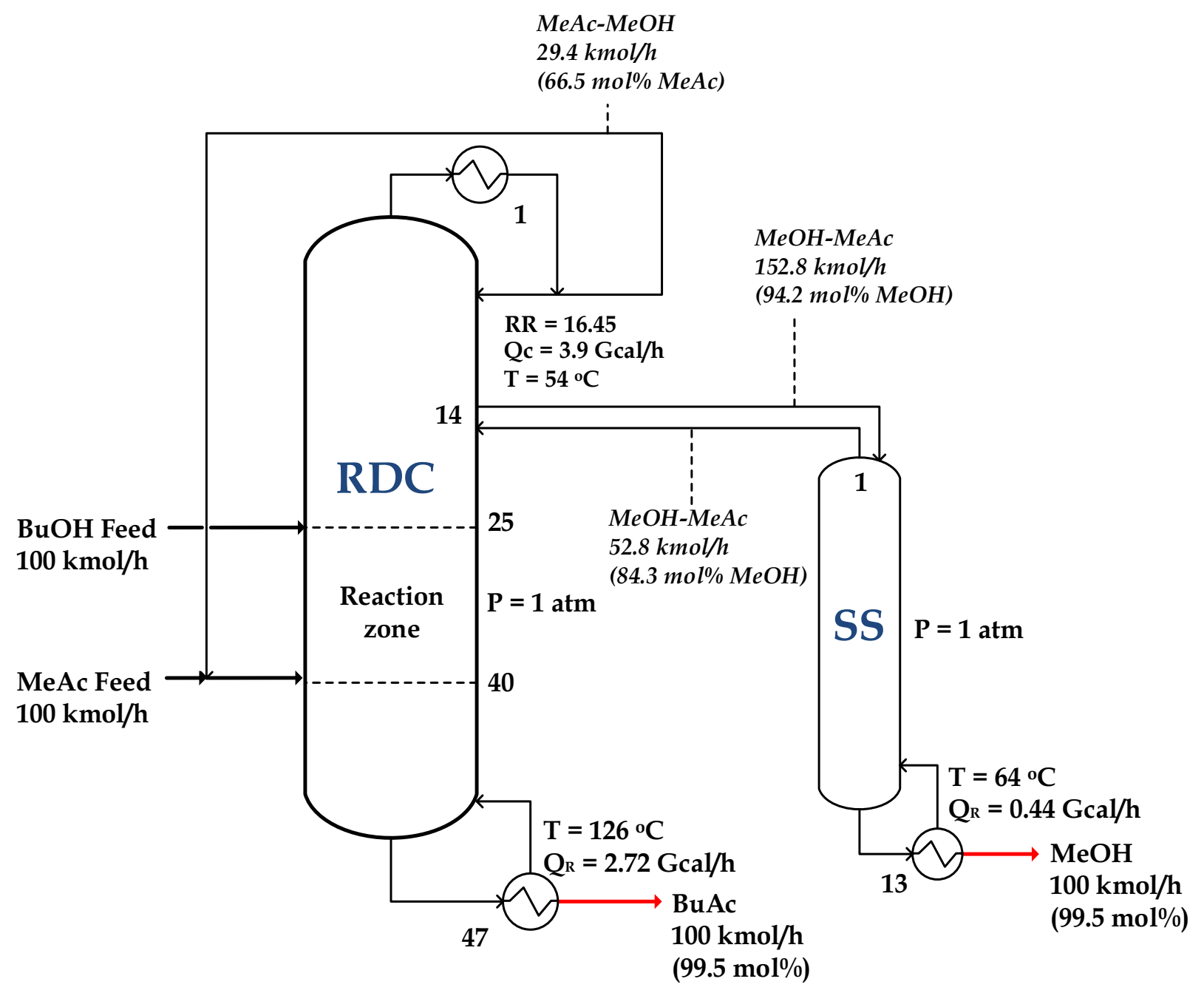

Fig. 8. Optimized TCRD configuration (RD+SS)

\subsection{Design and optimization of the $\mathrm{RD}+\mathrm{PV}$ hybrid process}

As discussed by Steinigeweg and Gmehling (2004), the low reaction rate and equilibrium constant of this transesterification reaction make the methyl acetate-methanol azeotrope produced in this reaction inevitable. Thus, it is necessary to combine the reactive distillation column with another separation process such as pervaporation in order to avoid the azeotrope barrier and obtain highpurity of methyl acetate at a high conversion rate. The first design of an $\mathrm{RD}+\mathrm{PV}$ hybrid for this 
transesterification process was presented by Steinigeweg and Gmehling (2004). They employed a pervaporation membrane to obtain a methyl-acetate-rich retentate to be recycled into the reactive distillation column. From their experimental results, they concluded that high conversion can only be expected when there is no methanol remaining in the retentate and revealed that the conversion of butanol increases when the methyl acetate concentration in the recycle stream increases. However, no detailed investigation of the optimal mass and energy balance of the RD+PV hybrid configuration was performed in their work.

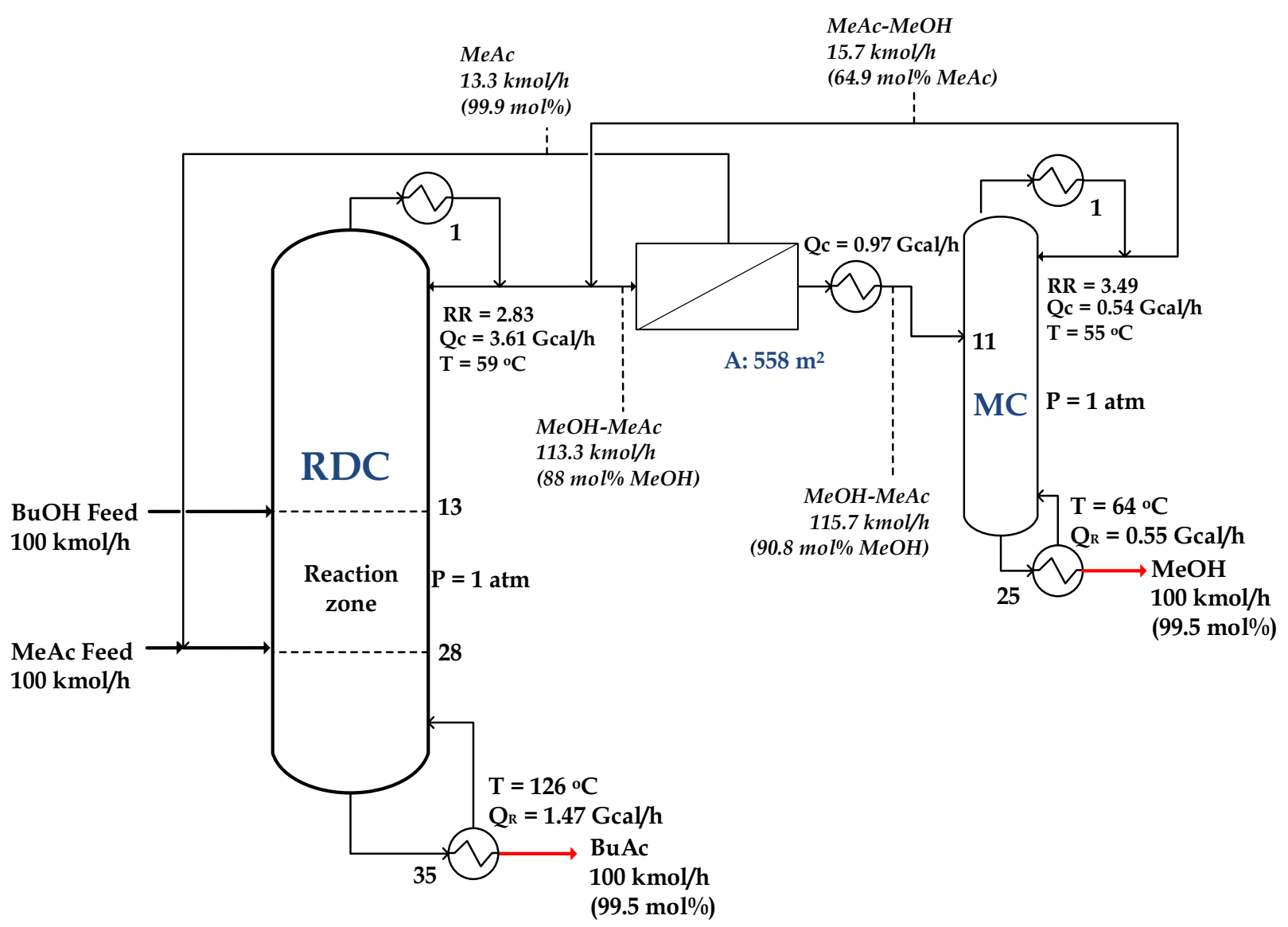

Fig. 9. Optimized RD+PV hybrid process 
In this work, the mass and energy balance of the RD+PV process was optimized. The optimized $\mathrm{RD}+\mathrm{PV}$ process can be seen in Fig. 9. Note that in the RD+PV process, an additional condenser is needed to condense the pervaporation permeate stream prior to entering the methanol column.

The selectivity of the commercial pervaporation membrane is too low to obtain pure methanol in the permeate stream. Therefore, as shown in Fig. 9, the permeate containing some methyl acetate is fed into the methanol column for further separation. In addition, the distillate from the methanol column that contains the methanol-methyl acetate azeotrope is recycled back to the pervaporation membrane along with the distillate stream from the reactive distillation column. The results show that the pervaporation membrane placed between the reactive distillation and methanol columns reduces the total reboiler duty of the process by $42 \%$ compared to the optimized conventional reactive distillation configuration (from 3.48 to $2.02 \mathrm{Gcal} / \mathrm{h}$ ).

\subsection{Proposed TCRD+PV hybrid process}

A thermally coupled TCRD $+\mathrm{PV}$ process is proposed to enhance the energy efficiency of butyl acetate production. The proposed TCRD+PV configuration is intended to take synergistic advantage of both TCRD and pervaporation by utilizing the full potential of thermal coupling while breaking the azeotropic composition of methyl acetate and methanol in the recycle stream. The proposed hybrid process was configured by placing the pervaporation membrane in the distillate stream (between the reactive distillation and side-stripper columns) while the structure of each column in the TCRD is the same as that the previous work by Wang et al. (2008). The recycle streams from the retentate and the liquid split ratio to the side-stripper column were optimized to minimize the total reboiler duty of the process. Fig. 10 shows the process flow sheet for the 
proposed TCRD $+\mathrm{PV}$ hybrid configuration with the optimized mass and energy balance. The distillate stream from the reactive distillation column is fed to the pervaporation membrane with a composition near the azeotrope point between methyl acetate and methanol. The high-purity butyl acetate retentate is then recycled to the reactive distillation column while the permeate goes to the side-stripper column to separate the methanol and methyl acetate. Note that a recycle stream of nearly pure methyl acetate is necessary to increase the conversion of the transesterification reaction by minimizing the accumulation of methanol, which would promote the forward reaction to produce n-butyl acetate.

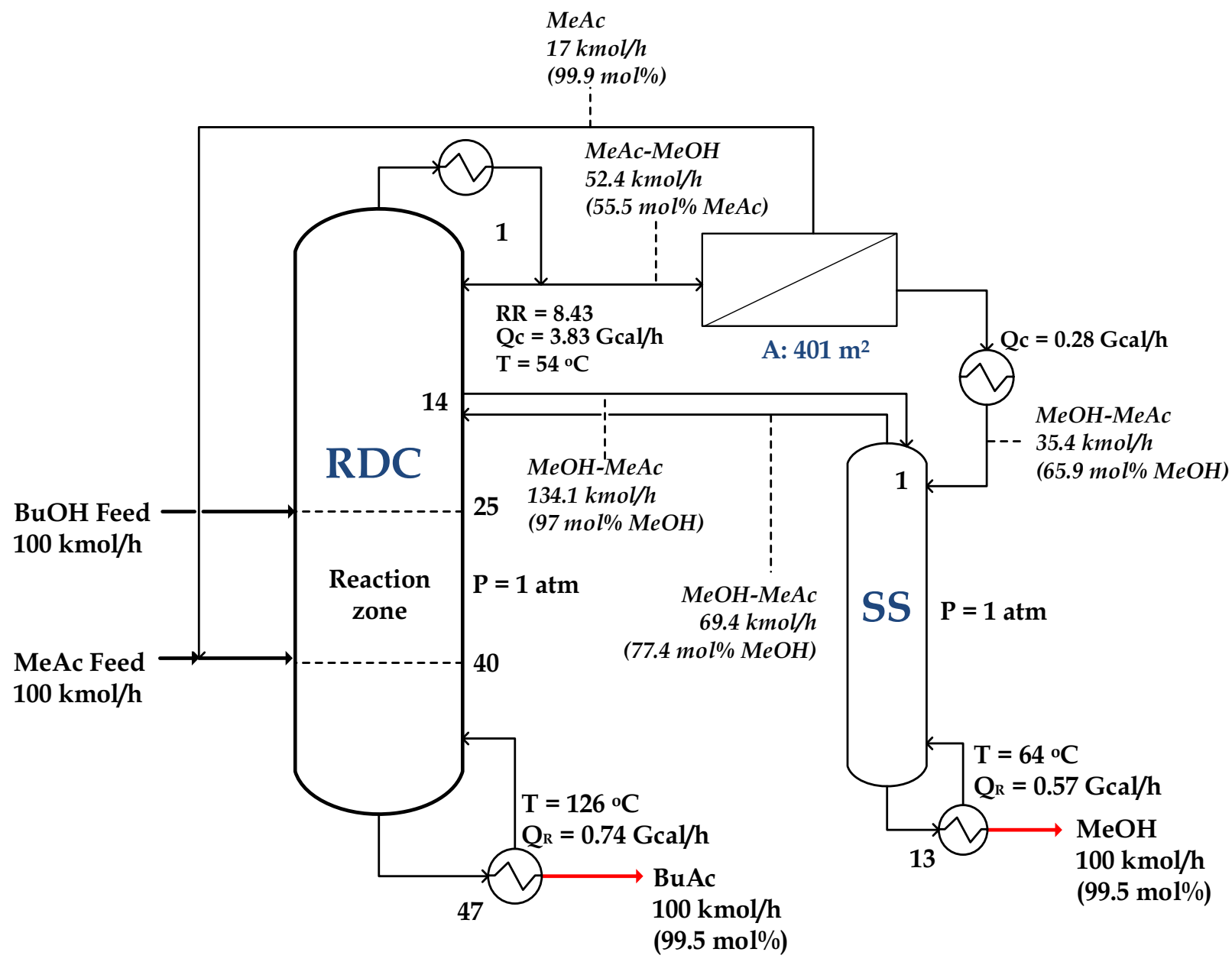

Fig. 10. Optimized TCRD + PV process 
Owing to its limited performance, the commercial pervaporation membrane does not appear as the final purification unit. Instead of producing pure methanol in the permeate stream, the commercial membrane provides nearly-pure methyl acetate in the retentate stream by allowing methanol to completely pass through it. The permeate stream still contains some methyl acetate. However, the enriched methanol concentration allows the side-stripper column to recover methanol using less separation energy.

The operability of the hybrid process also plays an important role in the further step. In kinetically controlled reactive distillation, the residence time in the reactive zone changes as the production rate varies. Key to controlling the process is maintaining an accurate stoichiometric balance between the feed compositions (Wang et al., 2011). This balance is essential for the smooth operation of an reactive distillation column (Luyben and Yu, 2009). Fig. 11 shows the reactant composition profiles of the reactive distillation columns (a) in the conventional reactive distillation design and (b) in the proposed TCRD+PV hybrid design. The concentration of butanol in the reactive zone is lower in the TCRD+PV than that in the conventional reactive distillation configuration, which indicates that a higher conversion of butanol into butyl acetate can be accomplished in the TCRD+PV configuration. Moreover, deviation from the stoichiometric condition (i.e., butanol: methyl acetate $=1: 1$ ) in the reaction zone is lower in the TCRD+PV design. This indicates that the proposed TCRD+PV configuration offers improved operability in terms of maintaining stoichiometric reactant conditions in the reaction zone. 

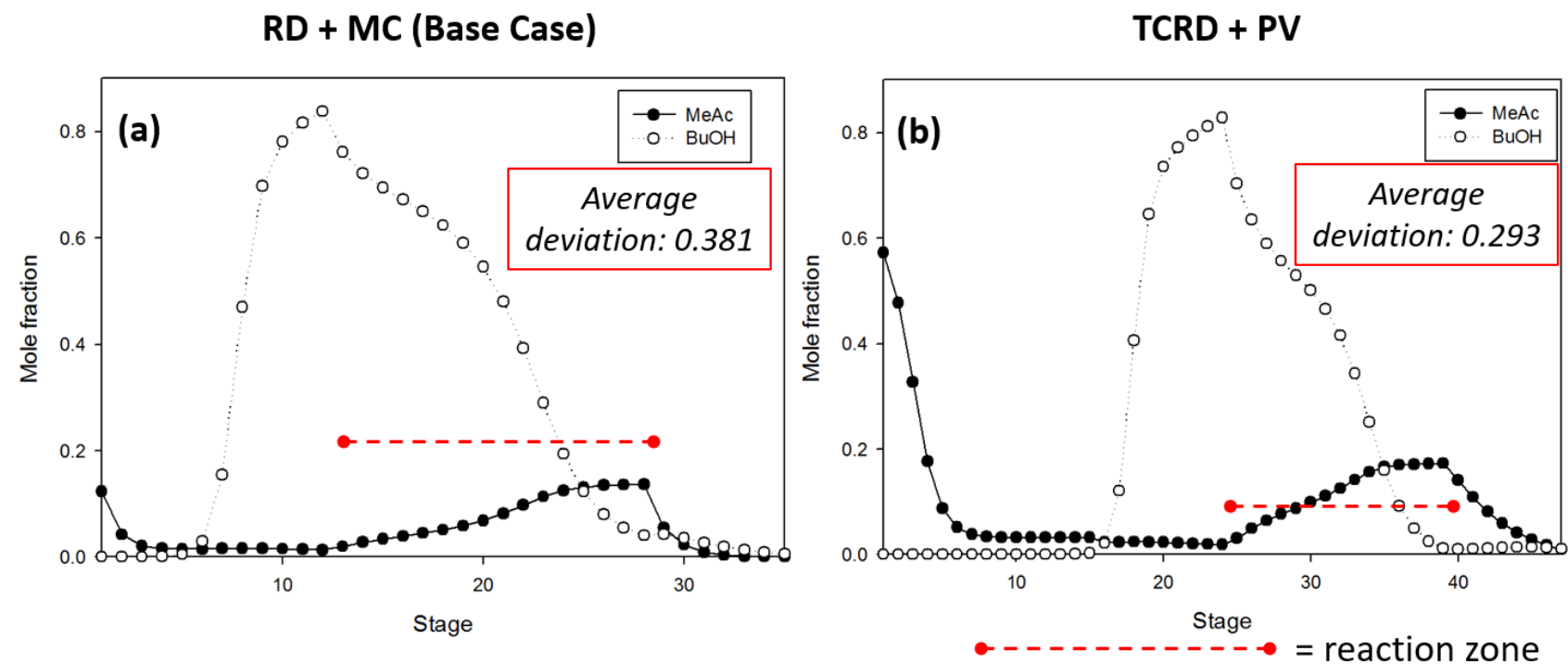

Fig. 11. Comparison of composition profiles of the reactive distillation column (a) in the conventional reactive distillation configuration (optimized) and (b) in the TCRD+PV configuration

\subsection{Performance evaluation and comparison}

Table 4 compares the performances of all the process configurations studied in this work. The optimized conventional reactive distillation design was chosen as a base case for evaluation of each configuration. The energy efficiency of the conventional reactive distillation and TCRD configurations is significantly improved by 48.1 and $44.9 \%$, respectively, compared to the corresponding configurations in the previous work (Wang et al., 2011) simply by optimizing several main process variables such as the recycle flow rate and the liquid split ratio. This dramatic improvement in both configurations is mainly due to the significantly reduced recycle stream to the reactive distillation column. In the TCRD configuration, an increased methanol concentration in the split stream is also obtained through optimization and contributes to the low reboiler duty 
of the side-stripper column. Thermal coupling of the reactive distillation column enhances the energy efficiency by $9.2 \%$.

Table 4. Performance comparison of all configurations studied in this work

\begin{tabular}{|c|c|c|c|c|c|c|}
\hline $\begin{array}{c}\text { Configuration } \\
\text { Variable }\end{array}$ & $\begin{array}{c}\text { Conv* } \\
\text { RD+MC }\end{array}$ & $\begin{array}{l}\text { TCRD* } \\
\text { RD+SS }\end{array}$ & $\begin{array}{l}\text { Conv(opt) } \\
\text { RD+MC }\end{array}$ & $\begin{array}{c}\text { TCRD(opt) } \\
\text { RD+SS }\end{array}$ & $\begin{array}{c}\text { Hybrid(opt) } \\
\text { RD+PV }\end{array}$ & $\begin{array}{c}\text { Proposed } \\
\text { TCRD+PV }\end{array}$ \\
\hline C-1 Reb (Gcal/h) & 5.69 & 4.27 & 2.85 & 2.72 & 1.47 & 0.74 \\
\hline C-2 Reb (Gcal/h) & 1.01 & 1.49 & 0.63 & 0.44 & 0.55 & 0.57 \\
\hline Total Reb (Gcal/h) & 6.7 & 5.73 & 3.48 & 3.16 & 2.02 & 1.29 \\
\hline Reb. Saving (\%) & -92.5 & -64.7 & Base Case & 9.2 & 41.9 & 63.8 \\
\hline PV Area $\left(\mathrm{m}^{2}\right)$ & - & - & - & - & 558 & 401 \\
\hline C-1 Cond (Gcal/h) & 6.44 & 6.49 & 3.59 & 3.9 & 3.61 & 3.83 \\
\hline C-2 Cond (Gcal/h) & 0.99 & - & 0.63 & - & 0.54 & - \\
\hline PV Cond (Gcal/h) & - & - & - & - & 0.97 & 0.28 \\
\hline Total Cond (Gcal/h) & 7.43 & 6.49 & 4.22 & 3.9 & 5.12 & 4.11 \\
\hline Recycle (kmol/h) & 104.7 & 98.3 & 22.6 & 29.4 & 13.3 & 17 \\
\hline Split ratio & - & 1.53 & - & 2.89 & - & 1.93 \\
\hline
\end{tabular}

Note: * the value for each configuration is obtained from the previous work (Wang et al., 2011).

More remarkable improvement is accomplished by applying pervaporation to the reactive distillation configuration. The reboiler duty of the process is reduced up to $41.9 \%$ by retrofitting of the conventional reactive distillation configuration to the RD+PV configuration. By introducing the pervaporation membrane, the azeotropic composition of the recycle stream, which is the main barrier to obtaining high-purity methyl acetate, was successfully avoided, and thus nearly-pure methyl acetate is recycled to the reactive distillation column to allow high conversion. 
Moreover, the proposed TCRD+PV configuration enhances the energy efficiency of the process significantly up to $63.8 \%$ compared to the base case (i.e., the optimized conventional reactive distillation configuration) and shows the synergistic effect of the TCRD and RD+PV configurations. The net amount of reboiler duty savings $(2.19 \mathrm{Gcal} / \mathrm{h})$ is higher than the simple sum of those from the TCRD and RD+PV configurations $(1.78 \mathrm{Gcal} / \mathrm{h})$.

Fig. 12 compares the butyl acetate, methanol, and methyl acetate composition profiles of the reactive distillation column in the TCRD and TCRD+PV configurations. The nearly-pure methyl acetate provided by pervaporation is beneficial for the side-stripper column in the proposed TCRD+PV configuration as it increases the methanol concentration of the liquid split stream (stage 14), shown as a red solid line in Fig. 12 (i.e., $94.2 \mathrm{~mol} \%$ in the TCRD configuration and $97 \mathrm{~mol} \%$ in the TCRD+PV configuration). It can also be seen from the red dashed line that the methyl acetate concentration in the TCRD+PV sequence is maintained at a low level in a wider range of the rectifying section and that the methanol concentration in the rectifying section is higher than that in the TCRD configuration. The reaction conversion at the end of the reaction zone is higher in the proposed TCRD+PV configuration compared to that in the TCRD configuration: the butyl acetate concentration increases from 80.2 to $90.4 \mathrm{~mol} \%$ (red dotted line), as can be seen from the composition profile. This is because the almost pure methyl acetate recycled to the reactive distillation column promotes the forward reaction and further reduces the accumulation of unreacted methyl acetate in the column, especially in the rectifying stages. In the TCRD configuration, the distillate (stage 1 from the reactive distillation column) is strictly optimized up to the azeotrope composition of methyl acetate-methanol mixture (66.5 mol\%) then recycled back to the reactive distillation column. Conversely, the TCRD+PV configuration allows a low 
concentration of methyl acetate $(55.5 \mathrm{~mol} \%)$, which is below the azeotrope composition, in the distillate stream. This also contributes to the reduced reboiler duty in the TCRD+PV configuration.

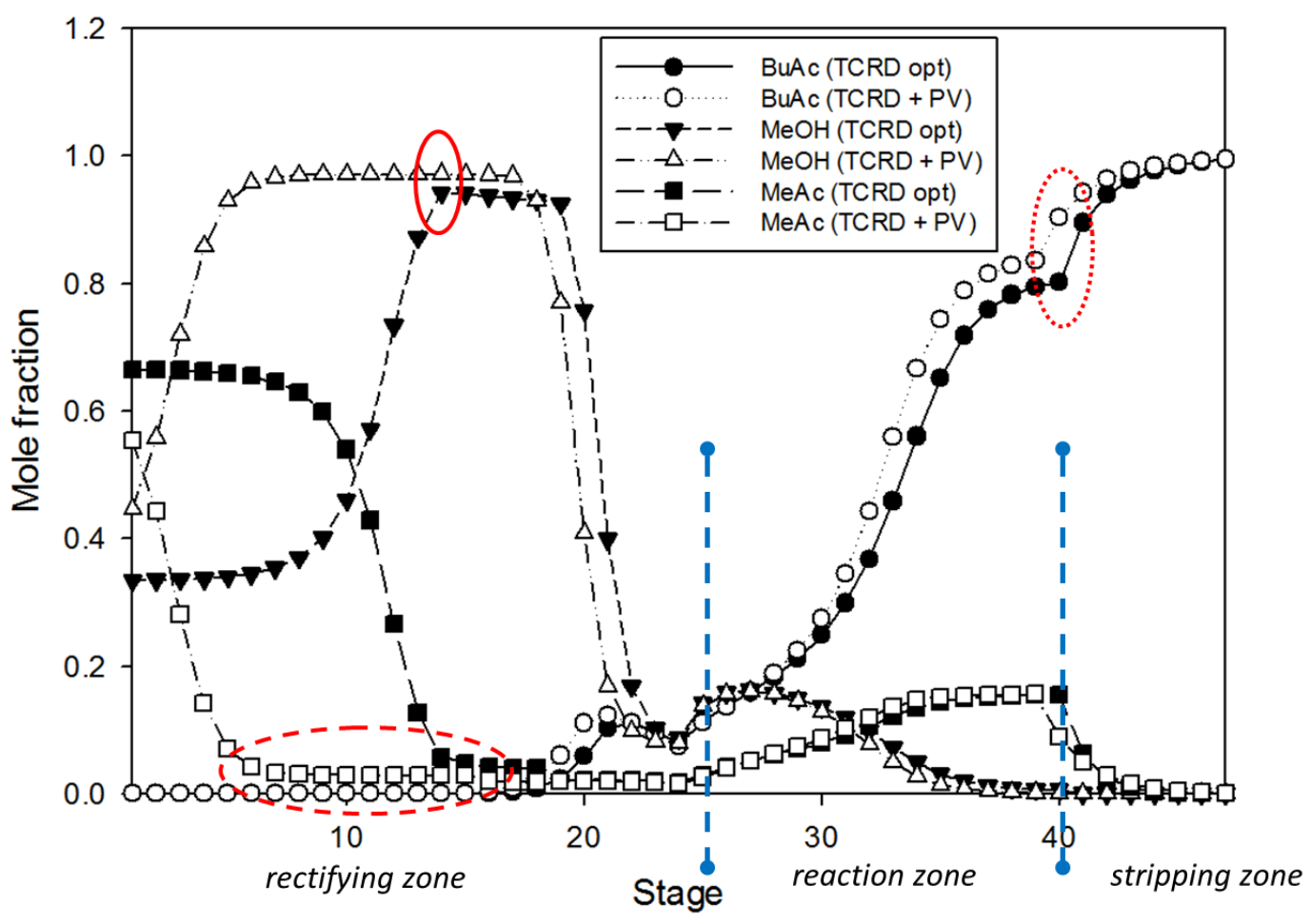

Fig. 12. Composition profile of the reactive distillation column in the TCRD and TCRD+PV configurations

In summary, the proposed TCRD+PV configuration is characterized by (1) a low recycle flow rate; (2) a high concentration of methanol in the liquid split stream; (3) a low concentration of methyl acetate in the rectifying stages; and (4) a high reaction conversion in the reactive distillation column, all of which are closely related to the remarkable synergistic improvement in the energy efficiency of the TCRD+PV configuration. Note that the energy saving of the proposed TCRD +PV configuration is based on the column structure of the previous work by Wang et al. 
(2011). Additional energy savings may be possible by rigorous optimization of the TCRD column structure.

\subsection{Economic Evaluation}

The economics of the different process configurations were evaluated in terms of operating cost, capital cost, and total annual cost (TAC). Table 4 shows the required membrane areas and energy consumptions (both reboiler and condenser duty) for all configurations considered in this study. A plant period of 10 years is assumed. A low-pressure steam $\left(160{ }^{\circ} \mathrm{C}, 5.2\right.$ bar $)$ was used for all reboilers because the base temperature is $126^{\circ} \mathrm{C}$. The reactive distillation column and methanol column operates with a condenser pressure of $1 \mathrm{~atm}$, which gives a reflux drum temperature around $54{ }^{\circ} \mathrm{C}$ and allows the use of cooling water in the condenser. Details of the method used to calculate the costs are given in the Appendix. Fig. 13 shows a comparison of the capital costs of the different process configurations studied. Optimization achieves a significant reduction of capital cost (up to $30 \%$ ) for both the conventional reactive distillation and the TCRD process. Since both the previous and optimized configurations use the same structure (i.e., the same stage number and allocation) for each corresponding column, the difference of capital cost is mainly due to the diameter of the distillation columns. A larger stream has to be recycled to the column, which leads to an increase in the physical size (i.e., diameter) of the column and the thermal requirement. As per the result from the size evaluation in Aspen Plus, the required diameter of the reactive distillation column is reduced upon optimization from 2.63 to $1.83 \mathrm{~m}$ and 2.26 to $1.79 \mathrm{~m}$ for the conventional $\mathrm{RD}+\mathrm{MC}$ and TCRD configurations, respectively. Moreover, the methanol and side-stripper column size in the optimized configurations is decreased from 0.82 to $0.67 \mathrm{~m}$ for the methanol column and from 
1.02 to $0.52 \mathrm{~m}$ for the side-stripper column.

Moreover, the optimized TCRD configuration shows slightly higher capital cost than the optimized $\mathrm{RD}+\mathrm{MC}$ configuration because the number of stages for the reactive distillation column in the TCRD design is higher than that in the RD+MC configuration. Although the total sum of the number of stages for the $\mathrm{RD}+\mathrm{MC}$ column (for the conventional reactive distillation) or sidestripper column (for the TCRD) are both 60 , the required diameter of the methanol column or sidestripper column $(0.5-0.7 \mathrm{~m})$ is much smaller than that of the reactive distillation column $(1.5-1.9$ $\mathrm{m})$.

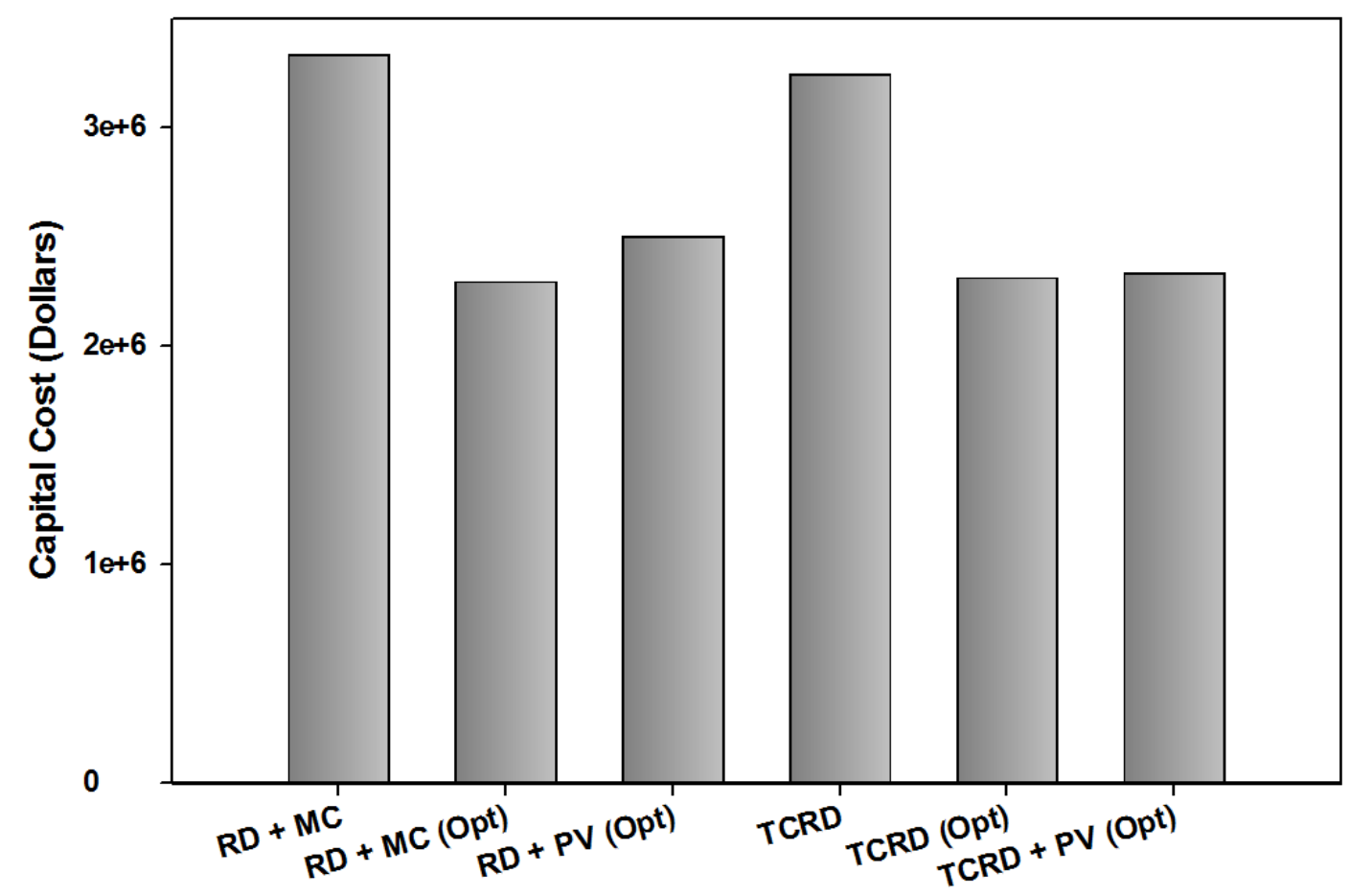

Fig. 13. Comparison of capital costs for different process configurations.

In contrast to the distillation column, pervaporation membrane separations units are known to increase costs due to the price of the membrane material and modules (Alzate, 2006; Koczka et al., 
2007). As seen in Fig. 13, the membrane has a significant impact on the capital cost due to the high price of the membrane material, modules, and its utilities (such as the vacuum pump and condenser). The RD+PV configuration has a $9 \%$ higher capital cost than that of the optimized $\mathrm{RD}+\mathrm{MC}$ configuration. The capital cost of the TCRD+PV configuration is slightly higher than the optimized TCRD configuration, but smaller than that of the RD+PV configuration simply because of the smaller membrane area required by the TCRD+PV configuration. Moreover, it has to be taken into account that pervaporation membrane with higher flux and selectivity would require a significantly lower membrane area for the same separation task. According to different membrane material, the cost of pervaporation membrane should also be considered.

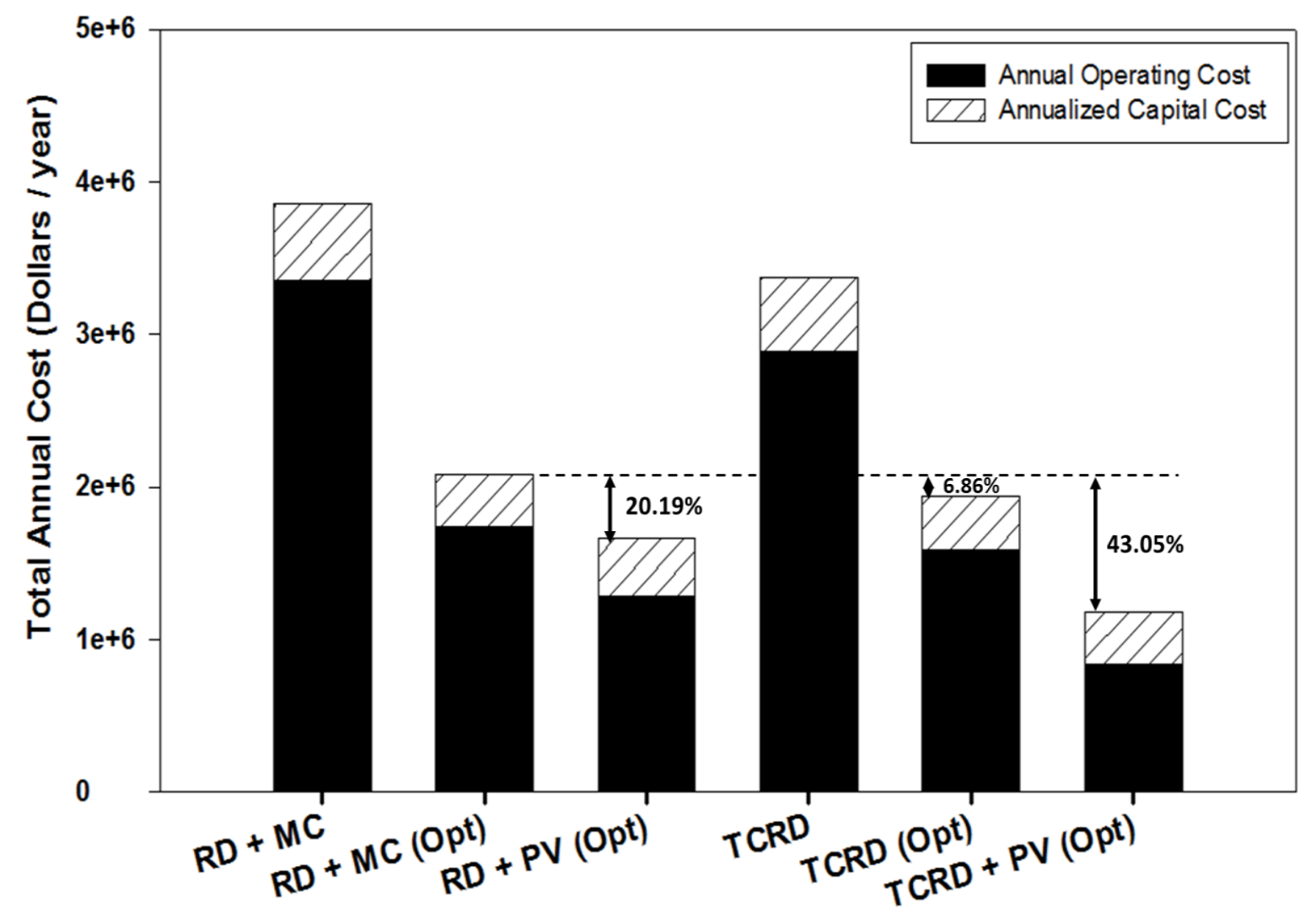

Fig. 14. Comparison of TACs for different process configurations. 
In addition to the capital cost, the TAC was also evaluated to take into account both operating and capital costs on the overall process economics. Fig. 14 shows a comparison of the TACs of the different process configurations. It was obvious that the proper optimization is essential to reduce the TAC for the same given process structures (i.e. conventional reactive distillation and TCRD). To highlight the contribution of the proposed hybrid design, conventional reactive distillation was used as the base case for the comparison in Fig. 14. Moreover, as indicated by the results for the $\mathrm{RD}+\mathrm{PV}$ and TCRD $+\mathrm{PV}$ configurations, the use of a pervaporation membrane is an effective strategy to reduce the TAC. Overall, the proposed TCRD+PV configuration shows the lowest TAC of all the configurations, with a TAC saving of $43.1 \%$ compared to the base case.

It can be concluded that, owing to the market availability of pervaporation membranes, the proposed TCRD+PV design can be applied to the commercial production of butyl acetate. Typical commercial pervaporation membranes seldom produce two pure products. More commonly, only the retentate or permeate component is provided with high purity. Since the proposed TCRD + PV assisted configuration takes this typical limitation into account, it can be applied as an attractive strategy to other industrial esterification and transesterification processes that involve equilibriumlimited reactions, low conversions, and azeotropic mixtures.

\section{Conclusions}

This work proposed a novel hybrid configuration combining TCRD and pervaporation (TCRD+PV) processes to enhance the energy efficiency of butyl acetate production. Applying the pervaporation membrane eliminated the azeotrope composition of the methanol-methyl acetate successfully in the recycle stream, allowing high reaction conversion in the reactive zone. It was 
also found that the recycle flow rate and the liquid split ratio are key variables for improving the energy efficiency of the conventional configuration. The energy efficiency was significantly improved by precise optimization of these variables for a fixed column structure. Despite the fact that the proposed TCRD+PV configuration has higher capital cost and complexity, it exhibited a synergistic combination of the advantages of both TCRD and RD+PV configurations: i.e., (1) a low recycle flow rate; (2) a high concentration of methanol in the liquid split stream, (3) a low concentration of methyl acetate in the rectifying stages; and (4) high reaction conversion in the reactive distillation column. As a result, the proposed TCRD+PV hybrid process reduced the energy consumption and TAC by $63.8 \%$ and $43.1 \%$, respectively. Moreover, the proposed TCRD+PV design offers better operability for maintaining the stoichiometric balance of the reactants in the reaction zone. To confirm its effectiveness, the proposed hybrid configuration can be extended to other similar chemical processes involving esterification and transesterification reactions and azeotrope mixtures. In addition, it has to be taken into account that the availability of the membrane for separation the azeotrope mixture is necessary for the development of proposed hybrid configuration.

\section{Acknowledgements}

This research was supported by the Basic Science Research Program through the National Research Foundation of Korea (NRF) funded by the Ministry of Education (2015R1D1A3A01015621) and by the Priority Research Centers Program through the National Research Foundation of Korea (NRF) funded by the Ministry of Education (2014R1A6A1031189). 


\section{Appendices}

\section{A. Column Cost Correlations}

\section{A.1. Sizing the column}

The column diameter was determined by the column flooding condition that fixes the upper limit of the vapor velocity. The operating velocity is usually between 70 and $90 \%$ of the flooding velocity (Premkumar and Rangaiah, 2009; Sinnott, 2005). In this study, $80 \%$ of the flooding velocity was used as the default.

\section{A.2. Capital cost (CC)}

Guthrie's modular method was applied (Biegler, 1997). In this study, a Chemical Engineering Plant Cost Index (CEPCI) of 576.1 (2014) was used for cost updating.

$\mathrm{CC}=$ bare module cost $(\mathrm{BMC})$ column $+\mathrm{BMC}$ wall $+\mathrm{BMC}$ tray stack $+\mathrm{BMC}$ condenser +

$\mathrm{BMC}$ reboiler (A. 1)

Updated $\mathrm{BMC}=\mathrm{UF} \times \mathrm{BC} \times(\mathrm{MPF}+\mathrm{MF}-1)$

where UF is the update factor: $U F=\frac{\text { present cost index }}{\text { bare cost index }}$

$\mathrm{BC}$ is the bare cost of the heat exchanger: $B C=B C_{0} x\left(\frac{A}{A_{0}}\right)^{\alpha}$

MPF is the material and pressure factor, and MF is the module factor (a typical value), which is affected by the base cost.

Area of the heat exchanger, $A=\frac{Q}{U \Delta T}$

Material and pressure factor: $\mathrm{MPF}=\mathrm{F}_{\mathrm{m}}+\mathrm{F}_{\mathrm{p}}+\mathrm{F}_{\mathrm{d}}$

\section{A.3. Operating cost (OC):}


Table S1. Utilities cost data (R. Turton, 2012).

\begin{tabular}{cc}
\hline Utility & Price $(\$ / \mathrm{GJ})$ \\
\hline Cooling Water & 0.35 \\
Steam (Low Pressure) & 13.28 \\
Electricity & 16.80 \\
\hline $\mathrm{C}_{\text {steam }}+\mathrm{C}_{\mathrm{CW}}+\mathrm{C}_{\text {electricity }}$ & \\
\hline
\end{tabular}

where $\mathrm{C}_{\text {steam }}$ is the cost of the steam, $\mathrm{C}_{\mathrm{CW}}$ is the cost of cooling water, and $\mathrm{C}_{\text {electricity }}$ is the cost of electricity.

\section{A.4. Total annual cost (TAC):}

The total annual cost includes the annual capital cost (ACC) and the annual operating cost (AOC). The annual investment cost was obtained from the literature and refers to the annual payments over the life of the project (Hicks and Chopey, 2012).

$A C C=C C\left[i(1+i)^{n} /(1+i)^{n}-1\right]$

where $i$ is the interest rate per year (8\%) and $n$ is the number of project years (10 years).

$T A C=A C C+A O C$

\section{B. Membrane cost correlations}

The membrane cost was provided by Lipnizki et al. (2002) as US $\$ 327.6 / \mathrm{m}^{2}$, updated with the CEPCI. The PV membrane used in this work is readily available from Sulzer Chemtech.

As mentioned earlier, the module used in this work was a plate frame module. Thus, the module cost was US\$2527.2/module. One module contains a $50 \mathrm{~m}^{2}$ membrane (Lipnizki et al., 2002). The annual maintenance and labor costs of the installations were assumed to be $10 \%$ of the total costs 
of the installations (Ji et al., 1994). In a work by Lipnizki et al. (2002) that used a Pervap membrane, the lifetime of the membrane was assumed as 2 years. Therefore, this membrane needs to be replaced five times during the depreciation period of 10 years for the total installation (Van Hoof et al., 2004).

The vacuum pump cost and condenser cost were calculated according to Ji et al. (1994) and are presented in the following equations.

$$
\begin{aligned}
& C_{V P}=4200 \frac{C E P C I 04}{C E P C I 94}\left(\frac{60 g_{T} R T_{0}}{3600 P_{0}}\right)^{0.55} \\
& C_{C O N D}=\frac{C E P C I 04}{C E P C I 94}\left(1176.7+128.1 A_{C O N D}\right)
\end{aligned}
$$

where

$$
A_{\text {COND }}=\Delta H_{G} / U \text { LMTD }
$$

In the pervaporation, since feed temperature decreases with the driving force for the component transportation, the feed mixture has to be re-heated to maintain the operating temperature for the uniformity of permeate composition and flow rate (Ishida and Nakagawa, 1985; Lipnizki et al., 2002). Since operating temperatures of pervaporation are lower than distillation column, this heat often obtained by using recovered heat from distillation, i.e. product stream (Colman et al., 1990; Del Pozo Gómez et al., 2008; Ishida and Nakagawa, 1985). The heat exchanger cost was calculated according to the Guthrie's modular method (Biegler, 1997). The utility cost was calculated for the vacuum pump and condensers. The cost of electricity and cooling water refers to Table S1.

$C_{U}=\operatorname{awh}\left[p c\left(W_{V P}\right)+W_{C O N D}\right]$

The power consumption of the vacuum pump $\left(W_{V P}\right)$ and the condenser were calculated according to Ji et al. (2004) using the following equation, which involves the total permeate flow. Because 
the permeate stream is condensed before the vacuum pump, the power consumption is overpredicted (but the influence of this on the total cost is small).

$$
W_{V P}=10 \% \frac{g_{T}}{3600} R T_{\text {intake }} \frac{k r}{k r-1}\left[\left(\frac{P_{D I S}}{P_{O P}}\right)^{\left(\frac{k r-1}{k r}\right)}-1\right]
$$

Water cooling consumption and steam consumption were calculated as follows:

$$
W_{C O N D}=\frac{w c \Delta H_{G} M W_{w}}{\Delta T_{C O N D} C_{p W}}
$$

\section{References}

Abrams, D.S., Prausnitz, J.M., 1975. Statistical thermodynamics of liquid mixtures: A new expression for the excess Gibbs energy of partly or completely miscible systems. AIChE Journal 21, 116-128.

Al-Malah, K.I.M., 2016. Aspen Plus: Chemical Engineering Applications. Wiley.

Alzate, J.F., 2006. Design and Performance of Two-Phase Flow Pervaporation and Hybrid Distillation Processes.

Beneke, D.A., Linninger, A.A., 2011. Graphical design and analysis of thermally coupled sidestream columns using column profile maps and temperature collocation. AIChE Journal 57, 2406-2420.

Biegler, L.T., Cuthrell, J.E., 1985. Improved infeasible path optimization for sequential modular simulators - II: the optimization algorithm. Computers \& Chemical Engineering 9, 257267.

Biegler, L.T., Grossmann, I.E. \& Westerberg, A.W. , 1997. Systematic methods of chemical process design. Prentice Hall Inc., New Jersey. 
Boggs, P.T., Tolle, J.W., 1995. Sequential quadratic programming. Acta numerica 4, 1-51.

Bożek-Winkler, E., Gmehling, J., 2006. Transesterification of Methyl Acetate and nButanol Catalyzed by Amberlyst 15. Industrial \& Engineering Chemistry Research 45, 6648-6654.

Chemtech, S., 2004. Pervaporation and vapor permeation technology, Application of pervaporation (brochure). Sulzer Chemtech, Switzerland.

Colman, D., Naylor, T., Pearce, G., 1990. Alcohol Dehydration by Pervaporation, in: Howell, J.A. (Ed.), The Membrane Alternative: Energy Implications for Industry: Watt Committee Report Number 21. The Watt Committee on Energy by Elsevier Applied Science, p. 99.

Del Pozo Gómez, M.T., Carreira, P.R., Repke, J.U., Klein, A., Brinkmann, T., Wozny, G., 2008. Study of a novel heat integrated hybrid pervaporation distillation process: Simulation and experiments. Computer Aided Chemical Engineering 25, 73-78.

Genduso, G., Amelio, A., Colombini, E., Luis, P., Degrève, J., Van der Bruggen, B., 2016. Retrofitting of extractive distillation columns with high flux, low separation factor membranes: A way to reduce the energy demand? Chemical Engineering Research and Design 109, 127-140.

Gorri, D., Ibáñez, R., Ortiz, I., 2006. Comparative study of the separation of methanolmethyl acetate mixtures by pervaporation and vapor permeation using a commercial membrane. Journal of Membrane Science 280, 582-593.

Harvianto, G.R., Ahmad, F., Nhien, L.C., Lee, M., 2016. Vapor permeation-distillation hybrid processes for cost-effective isopropanol dehydration: modeling, simulation and optimization. Journal of Membrane Science 497, 108-119.

Hicks, T., Chopey, N., 2012. Handbook of Chemical Engineering Calculations, Fourth Edition. McGraw Hill Professional. 
Ignat, R.M., Kiss, A.A., 2013. Optimal design, dynamics and control of a reactive DWC for biodiesel production. Chemical Engineering Research and Design 91, 1760-1767.

Ishida, M., Nakagawa, N., 1985. Exergy analysis of a pervaporation system and its combination with a distillation column based on an energy utilization diagram. Journal of Membrane Science 24, 271-283.

Ji, W., Hilaly, A., Sikdar, S.K., Hwang, S.-T., 1994. Optimization of multicomponent pervaporation for removal of volatile organic compounds from water. Journal of Membrane Science 97, 109-125.

Jiménez, L., Costa-López, J., 2002. The Production of Butyl Acetate and Methanol via Reactive and Extractive Distillation. II. Process Modeling, Dynamic Simulation, and Control Strategy. Industrial \& Engineering Chemistry Research 41, 6735-6744.

Jiménez, L., Garvín, A., Costa-López, J., 2002. The Production of Butyl Acetate and Methanol via Reactive and Extractive Distillation. I. Chemical Equilibrium, Kinetics, and MassTransfer Issues. Industrial \& Engineering Chemistry Research 41, 6663-6669.

Kiss, A.A., Ignat, R.M., 2012. Enhanced methanol recovery and glycerol separation in biodiesel production - DWC makes it happen. Applied Energy 99, 146-153.

Kiss, A.A., Suszwalak, D.J.P.C., 2012. Enhanced bioethanol dehydration by extractive and azeotropic distillation in dividing-wall columns. Separation and Purification Technology 86, 7078.

Koczka, K., Mizsey, P., Fonyo, Z., 2007. Rigorous modelling and optimization of hybrid separation processes based on pervaporation. Central European Journal of Chemistry 5, 11241147. 
Kujawski, W., 2000. Application of pervaporation and vapor permeation in environmental protection. Polish Journal of Environmental Studies 9, 13-26.

Lin, Y.D.C., J.H.; Huang, H.; Yu, C., 2006. Process Alternative for Methyl Acetate Conversion Using Reactive Distillation: Transesterification Versus Hydrolysis, AICHE Annual Meeting, San Francisco.

Lipnizki, F., Olsson, J., Trägårdh, G., 2002. Scale-up of pervaporation for the recovery of natural aroma compounds in the food industry Part 2: optimisation and integration. Journal of Food Engineering 54, 197-205.

Liu, K., Tong, Z., Liu, L., Feng, X., 2005. Separation of organic compounds from water by pervaporation in the production of n-butyl acetate via esterification by reactive distillation. Journal of Membrane Science 256, 193-201.

Long, N.V.D., Lee, M., 2014. Review of Retrofitting Distillation Columns Using Thermally Coupled Distillation Sequences and Dividing Wall Columns to Improve Energy Efficiency. Jounal of Chemical Engineering of Japan 47, 87-108.

Lu, Y.-y., Hu, Y.-d., Xu, D.-m., Wu, L.-y., 2006. Optimum design of reverse osmosis seawater desalination system considering membrane cleaning and replacing. Journal of Membrane Science 282, 7-13.

Luyben, W.L., Pszalgowski, K.M., Schaefer, M.R., Siddons, C., 2004. Design and Control of Conventional and Reactive Distillation Processes for the Production of Butyl Acetate. Industrial \& Engineering Chemistry Research 43, 8014-8025.

Luyben, W.L., Yu, C.-C., 2009. Reactive distillation design and control. John Wiley \& Sons. 
More, R.K., Bulasara, V.K., Uppaluri, R., Banjara, V.R., 2010. Optimization of crude distillation system using aspen plus: Effect of binary feed selection on grass-root design. Chemical Engineering Research and Design 88, 121-134.

Naidu, Y., Malik, R.K., 2011. A generalized methodology for optimal configurations of hybrid distillation-pervaporation processes. Chemical Engineering Research and Design 89, 13481361.

Premkumar, R., Rangaiah, G.P., 2009. Retrofitting conventional column systems to dividing-Wall Columns. Chemical Engineering Research and Design 87, 47-60.

R. Turton, R.C.B., W.B. Whiting, J.A. Shaeiwitz, D. Bhattacharyya, 2012. Analysis, synthesis and design of chemical processes, 4th ed. Prentice Hall, Upper Saddle River, NJ.

Sain, S., Dinçer, S., Savaşçy1, Ö.T., 1998. Pervaporation of methanol-methyl acetate binary mixtures. Chemical Engineering and Processing: Process Intensification 37, 203-206.

Schefflan, R., 2011. Teach Yourself the Basics of Aspen Plus. John Wiley \& Sons, Inc., Hoboken, New Jersey.

Sinnott, R.K., 2005. Chemical Engineering Design 4th ed. Elsevier Butterworth Heinemann, Oxford.

Steinigeweg, S., Gmehling, J., 2004. Transesterification processes by combination of reactive distillation and pervaporation. Chemical Engineering and Processing: Process Intensification 43, 447-456.

Švandová, Z., Markoš, J., 2011. Theoretical study on transesterification in a combined process consisting of a reactive distillation column and a pervaporation unit. Chemical Papers 65, $167-176$. 
Taylor, R., Krishna, R., 2000. Modelling reactive distillation. Chemical Engineering Science 55, 5183-5229.

Van Duc Long, N., Lee, M., 2013. Debottlenecking the Retrofitted Thermally Coupled Distillation Sequence. Industrial \& Engineering Chemistry Research 52, 12635-12645.

Van Hoof, V., Van den Abeele, L., Buekenhoudt, A., Dotremont, C., Leysen, R., 2004. Economic comparison between azeotropic distillation and different hybrid systems combining distillation with pervaporation for the dehydration of isopropanol. Separation and Purification Technology 37, 33-49.

Wang, S.-J., Huang, H.-P., Yu, C.-C., 2011. Design and Control of a Heat-Integrated Reactive Distillation Process to Produce Methanol and n-Butyl Acetate. Industrial \& Engineering Chemistry Research 50, 1321-1329.

Wang, S.-J., Wong, D.S.H., Yu, S.-W., 2008. Design and control of transesterification reactive distillation with thermal coupling. Computers \& Chemical Engineering 32, 3030-3037. 